\title{
Cognitive Decline in Alzheimer's Disease Is Associated with Selective Changes in Calcineurin/NFAT Signaling
}

\author{
Hafiz Mohmmad Abdul, ${ }^{1}$ Michelle A. Sama, ${ }^{2}$ Jennifer L. Furman, ${ }^{2}$ Diana M. Mathis, ${ }^{3}$ Tina L. Beckett, ${ }^{1}$ \\ Adam M. Weidner, ${ }^{4}$ Ela S. Patel, ${ }^{1}$ Irfan Baig, ${ }^{1}$ M. Paul Murphy, ${ }^{1,4}$ Harry LeVine 3rd, ${ }^{1,4}$ Susan D. Kraner, ${ }^{2}$ \\ and Christopher M. Norris ${ }^{1,2}$ \\ ${ }^{1}$ The Sanders-Brown Center on Aging, ${ }^{2}$ Department of Molecular and Biomedical Pharmacology, ${ }^{3}$ Graduate Center for Gerontology, and ${ }^{4}$ Department of \\ Molecular and Cellular Biochemistry, University of Kentucky, Lexington, Kentucky 40536
}

Upon activation by calcineurin, the nuclear factor of activated T-cells (NFAT) translocates to the nucleus and guides the transcription of numerous molecules involved in inflammation and $\mathrm{Ca}^{2+}$ dysregulation, both of which are prominent features of Alzheimer's disease (AD). However, NFAT signaling in AD remains relatively uninvestigated. Using isolated cytosolic and nuclear fractions prepared from rapid-autopsy postmortem human brain tissue, we show that NFATs 1 and 3 shifted to nuclear compartments in the hippocampus at different stages of neuropathology and cognitive decline, whereas NFAT2 remained unchanged. NFAT1 exhibited greater association with isolated nuclear fractions in subjects with mild cognitive impairment (MCI), whereas NFAT3 showed a strong nuclear bias in subjects with severe dementia and AD. Similar to NFAT1, calcineurin-A $\alpha$ also exhibited a nuclear bias in the early stages of cognitive decline. But, unlike NFAT1 and similar to NFAT3, the nuclear bias for calcineurin became more pronounced as cognition worsened. Changes in calcineurin/NFAT3 were directly correlated to soluble amyloid- $\beta\left(\mathrm{A} \beta_{(1-42)}\right)$ levels in postmortem hippocampus, and oligomeric $\mathrm{A} \beta$, in particular, robustly stimulated NFAT activation in primary rat astrocyte cultures. Oligomeric $\mathrm{A} \beta$ also caused a significant reduction in excitatory amino acid transporter 2 (EAAT2) protein levels in astrocyte cultures, which was blocked by NFAT inhibition. Moreover, inhibition of astrocytic NFAT activity in mixed cultures ameliorated $\mathrm{A} \beta$-dependent elevations in glutamate and neuronal death. The results suggest that NFAT signaling is selectively altered in AD and may play an important role in driving $\mathrm{A} \beta$-mediated neurodegeneration.

\section{Introduction}

Calcineurin $(\mathrm{CN})$ is a $\mathrm{Ca}^{2+} /$ calmodulin-dependent protein phosphatase, perhaps most widely known for its essential role in regulating cytokine expression in lymphocytes through activation of the transcription factor, nuclear factor of activated T-cells (NFAT) (Crabtree and Olson, 2002). In peripheral tissues, CN controls the nuclear import of at least four NFAT isoforms (NFATs 1-4), which exhibit overlapping and distinct functions in different stages of development and inflammation (Horsley and Pavlath, 2002). In addition to its many beneficial functions, the CN/NFAT pathway can also give rise to dysfunctional cellular phenotypes and perpetuate numerous peripheral immune/inflammatory disorders when not regulated properly (Ferraccioli et al., 2005; Heineke and Molkentin, 2006; Kaminuma, 2008).

$\mathrm{CN}$ is also widely recognized for its abundance in brain and for its numerous beneficial and deleterious actions in neural cells (Groth et al., 2003; Sierra-Paredes and Sierra-Marcuno, 2008). NFATs, in contrast, have received far less attention for their con-

Received March 4, 2009; revised Aug. 20, 2009; accepted Sept. 2, 2009.

This work was supported by National Institutes of Health Grants AG024190, AG027297, AG028383, and AG010836 and a gift from the Kleberg Foundation. We thank Drs. Rodney Guttmann, Eric Blalock, and Steven Estus for critical reading of this manuscript and Dr. William Markesbery for technical advice.

Correspondence should be addressed to Dr. Christopher M. Norris, 131 Sanders-Brown Building, 800 South Limestone Street, University of Kentucky College of Medicine, Lexington, KY 40536. E-mail: cnorr2@email.uky.edu. DOI:10.1523/JNEUROSCI.1064-09.2009

Copyright $\odot 2009$ Society for Neuroscience $\quad 0270-6474 / 09 / 2912957-13 \$ 15.00 / 0$ tribution to neurological function. Recently, several reports have linked NFAT activation in nervous tissue to immune/inflammatory cascades commonly associated with aging and neurodegenerative disease (Fernandez et al., 2007; Canellada et al., 2008; Sama et al., 2008). Alzheimer's disease (AD), in particular, is associated with a strong neuroinflammatory response (Mrak and Griffin, 2005a; Wyss-Coray, 2006; Van Eldik et al., 2007) and recent studies observed an increase in hippocampal $\mathrm{CN}$ activity in human $\mathrm{AD}$ subjects and in $\mathrm{AD}$ model mice (Liu et al., 2005; Dineley et al., 2007), suggesting the possible involvement of NFATs in the disease process.

Previously, we discovered intense $\mathrm{CN}$ expression localized to activated astrocytes surrounding amyloid plaques in $\mathrm{AD}$ model mice (Norris et al., 2005). Hyperactivation of $\mathrm{CN}$ in astrocytes triggered the induction of numerous genes associated with aging and incipient AD (Blalock et al., 2003, 2004; Norris et al., 2005). Many of the identified genes were related to immune/inflammatory responses, again, suggesting the involvement of NFAT transcription factors. Despite these findings, little to no information is available regarding NFAT isoforms or NFAT signaling properties with $\mathrm{AD}$. This information seems important from a therapeutic standpoint, in that the selective inhibition of NFAT activity may be associated with a more favorable toxicity profile, relative to classic $\mathrm{CN}$ inhibitors (at least in animal models) (Noguchi et al., 2004).

In the present work, we provide some of the first evidence that different NFAT isoforms are recruited to hippocampal nuclear 
Table 1. Subject information

\begin{tabular}{lllllcc}
\hline Group & $N$ & Male/female & Age (years) & PMI (h) & Braak stage & MMSE \\
\hline Control & 12 & $2 / 10$ & $88.67 \pm 6.73$ & $2.92 \pm 0.64$ & $1.33 \pm 1.23$ & $29 \pm 1.21$ \\
MCl & $10^{a}$ & $5 / 5$ & $89.5 \pm 5.46$ & $3.79 \pm 2.28$ & $3.5 \pm 1.18^{b}$ & $24.1 \pm 3.8^{c}$ \\
AD & 18 & $9 / 9$ & $79.83 \pm 7.59^{d}$ & $3.23 \pm 0.88$ & $5.56 \pm 1.15^{e, f}$ & $9.25 \pm 8.01^{e, f}$
\end{tabular}

Values for age, PMI, Braak, and MMSE are given as mean \pm SD.

${ }^{a} n=4$ for cerebellum samples. ${ }^{b} p<0.001$ versus control; ${ }^{c} p<0.05$ versus control; ${ }^{d} p<0.01$ versus control; ${ }^{e} p<0.0001$ versus control; $f_{p}<0.001$ versus MCl.

compartments at different stages of cognitive dysfunction associated with AD. A wave of NFAT1 activation occurred relatively early in cognitive decline, but then fell to below normal control levels as dementia and AD worsened. Conversely, NFAT3 exhibited a clear nuclear bias in the later stages of dementia that corresponded directly to soluble amyloid- $\beta\left(\mathrm{A} \beta_{(1-42)}\right)$ levels. In primary astrocytes, NFAT activation was rapidly and robustly stimulated by oligomeric $\mathrm{A} \beta$ and contributed to $\mathrm{A} \beta$-mediated neurodegeneration, indicating a causative relationship between amyloid toxicity and NFAT signaling. Together, the results offer new insight to the molecular cascades that emerge during the progression of $\mathrm{AD}$ and suggest new therapeutic targets for the prevention of neurodegeneration and dementia.

\section{Materials and Methods}

Subjects. All subjects were participants in the University of Kentucky's Alzheimer 's Disease Center Autopsy program. These participants were followed for at least 2 years (many for $>10$ years) before death and had no history of substance abuse, head injury, encephalitis, meningitis, epilepsy, stroke/transient ischemic attack, chronic infectious disease, or any other major psychiatric illness that limited cognitive performance or influenced affect. Standardized mental status testing [e.g., the MiniMental State Examination (MMSE)] and neurologic and physical examinations were performed on an annual or biannual basis. The MMSE conducted closest to the date of death was the most consistently available cognitive measure across all patients and was used in the present study as an indicator of overall cognitive status. At autopsy (usually $\sim 3 \mathrm{~h}$ after death), tissue from multiple brain regions was processed for neuropathologic evaluations as described previously (Nelson et al., 2007). AD subjects used in this study met the standard clinical and histophathological criteria for diagnosis of AD (McKhann et al., 1984; Mirra et al., 1991, National Institute on Aging, and Reagan Institute Working Group on Diagnostic Criteria for the Neuropathological Assessment of Alzheimer's Disease, 1997). All control subjects were at Braak stage three or lower and typically scored 28 or higher on the MMSE. Nondemented subjects exhibiting age- and education-corrected objective memory deficits, but otherwise intact cognitive function and daily living skills, were classified as mild cognitive impairment (MCI) cases, as discussed previously (Petersen et al., 1999). Finally, six of our AD cases also exhibited some degree of Lewy body pathology. However, these cases did not differ significantly from the other $\mathrm{AD}$ cases on any of the measured biological markers and were therefore included in the $\mathrm{AD}$ group for statistical comparisons to control and MCI groups. Additional information on control, MCI, and AD cases is provided in Table 1.

Preparation of cell extracts from human brain tissue. At autopsy, tissue samples were flash-frozen in liquid nitrogen and stored at $-80^{\circ} \mathrm{C}$ until use. Cytosolic and nuclear fractions from hippocampal and cerebellar tissue samples were prepared with modifications of the protocol used by Ohlsson and coworkers (Ohlsson and Edlund, 1986). Briefly, $1 \mathrm{~g}$ of brain tissue was homogenized in buffer A [25 mM HEPES, pH 7.0, $25 \mathrm{~mm} \mathrm{KCl}$, $5 \mathrm{~mm} \mathrm{MgCl}_{2}, 0.05 \mathrm{~mm}$ EDTA, 10\% glycerol, $0.1 \% \mathrm{NP}-40$, and $1 \mathrm{~mm}$ dithiothreitol (DTT), phosphatase inhibitor, protease inhibitor, calpain inhibitors] and centrifuged for $10 \mathrm{~m}$ at $3000 \mathrm{rpm}\left(4^{\circ} \mathrm{C}\right)$. The resulting pellet was resuspended in Buffer C [50 mm HEPES, pH 7.6, $50 \mathrm{~mm} \mathrm{KCl,}$ $0.1 \mathrm{~mm}$ EDTA, $10 \%$ glycerol, $1 \mathrm{~mm}$ dithiothreitol, phosphatase inhibitor, protease inhibitor, calpain inhibitors, and $0.3 \mathrm{~m}$ ammonium sulfate], incubated on a rocking platform for $15 \mathrm{~m}\left(4^{\circ} \mathrm{C}\right)$ and then ultracentri- fuged at $37,000 \mathrm{rpm}$ for $15 \mathrm{~m}$ at $4^{\circ} \mathrm{C}$ (Beckman TL-100 tabletop ultracentrifuge, TLA 100.2 rotor) to remove nuclear debris. Proteins in the supernatant were precipitated by adding an equal volume of $3 \mathrm{M}$ ammonium sulfate, incubated on a rocking platform for $15 \mathrm{~min}$ at $4^{\circ} \mathrm{C}$, and ultracentrifuged at 37,000 rpm for $15 \mathrm{~min}$. The pellet obtained, which contained the nuclear fraction, was resuspended in $500 \mu \mathrm{l}$ of buffer $\mathrm{C}$ and stored at $-80^{\circ} \mathrm{C}$ until use. The supernatant collected from the initial 3000 rpm centrifugation step described above was processed through a series of three 15 min ultracentrifugation $(37,000 \mathrm{rpm})$ steps. After the first spin, the pellet obtained contained the membrane fraction (resuspended in $0.3 \mathrm{M}$ sucrose buffer and stored at $-80^{\circ} \mathrm{C}$ until use) and buffer $\mathrm{B}[0.3 \mathrm{M}$ HEPES, pH 7.6, $50 \mathrm{~mm} \mathrm{KCl,} 0.1 \mathrm{~mm}$ EDTA, $1 \mathrm{~mm}$ DTT, phosphatase inhibitor, protease inhibitor, calpain inhibitors] was added to the supernatant at $1 / 10^{\text {th }}$ the volume and spun a second time. The resulting supernatant was combined with $0.3 \mathrm{~g} / \mathrm{ml}$ ammonium sulfate for protein precipitation and then spun a third time. The resulting pellet, which contained the cytosolic fraction, was resuspended in buffer $\mathrm{C}$ and stored at $-80^{\circ} \mathrm{C}$ until use.

Western blot analysis. Protein concentration in cytosolic and nuclear fractions (and in some cases membrane fractions) was determined by the Lowry method and the samples loaded into individual lanes of a Bio-Rad gradient gel $(4-20 \%)$ with protein concentrations held constant across lanes. Proteins were resolved by electrophoresis and transferred to PVDF membranes for quantitative Western blot. Membranes were incubated at $4^{\circ} \mathrm{C}$ overnight in I-Bloc (Tropix) along with primary antibodies, which included: anti-CN-A $\alpha$ (1:3000) and anti-CN-A $\beta$ (1:3000) (both from EMD Biochemicals); anti-histone3 (1:10,000) (Sigma-Aldrich); antiNFAT2 (1:1000) (BD PharMingen); anti-EAAT2 (1:1000) (Santa Cruz Biotechnology); and anti-GSK3- $\beta$ (1:3000), anti-NFAT1 (1:1000), and anti-NFAT3 $(1: 10,000)$ (all from Abcam). Primary antibodies were tagged with the appropriate HRP-conjugated secondary antibody, diluted in I-Bloc at 1:10,000, and detected using the ECL-plus Western kit (GE Healthcare). Protein levels were quantified using a Storm 860 Molecular Imager.

$A \beta$ measurement in postmortem tissue. The solubility of $\mathrm{A} \beta$ was measured by a standard three-step serial extraction, as described previously (McGowan et al., 2005; Murphy et al., 2007). Briefly, brain tissue was first Polytron-homogenized in standard PBS buffer $(1.0 \mathrm{ml} / 150 \mathrm{mg}$ tissue $)$ including a complete protease inhibitor mixture (Amresco). Samples were centrifuged at $14,000 \times g$ for $30 \mathrm{~min}$ at $4^{\circ} \mathrm{C}$, and the supernatant collected. The pellet was reextracted by sonication in $2 \%$ SDS and centrifuged at $14,000 \times g$ for $30 \mathrm{~min}$ at room temperature. The supernatant was again collected, and the remaining pellet was extracted by sonication in $70 \%$ formic acid and centrifuged at $14,000 \times g$ for $1 \mathrm{~h}$. Sample extracts were then stored at $-80^{\circ} \mathrm{C}$ until the time of ELISA. Thawed SDS-soluble fractions were diluted in AC buffer [0.02 $\mathrm{M}$ sodium phosphate buffer, $\mathrm{pH}$ 7, $0.4 \mathrm{M} \mathrm{NaCl}, 2$ mм EDTA, 0.4\% Block Ace, 0.2\% BSA, 0.05\% 3-[(3cholamidopropyl)dimethylammonio]-1-propanesulfonate, and $0.05 \%$ $\mathrm{NaN} 3$ ]. A $\beta$ standard curves were prepared using synthetic, monomeric peptide (rPeptides); standards and samples were run in duplicate. Immulon 4HBX ELISA antibody-coated plates $(0.5 \mu \mathrm{g} /$ well in PBS, overnight) were blocked with Synblock (Serotec) for $2 \mathrm{~h}$ at room temperature. Antibodies used were $A b 9$ [human sequence $A \beta_{(1-16)}, 2.1 .3$ (end specific for $\left.\mathrm{A} \beta_{(42)}\right)$ or $4 \mathrm{G} 8\left(\mathrm{~A} \beta_{(17-24)}\right.$; Covance). After development with TMB reagent (KPL), plates were stopped with $6 \% o$-phosphoric acid and read at $450 \mathrm{~nm}$ using a BioTek multiwell plate reader.

Primary cell culture. Primary astrocyte and mixed hippocampal cultures were prepared from E18 Sprague Dawley rat pups as described previously (Sama et al., 2008). Embryonic primary cultures were used because CN/NFAT signaling has been well characterized in this model (Sama et al., 2008). And although several studies have revealed important functional differences between astrocytes cultured from neonatal tissue and adult tissue, we found that CN/NFAT activation in both cell culture models is qualitatively and quantitatively similar after stimulation with a variety of inflammatory mediators and $\mathrm{Ca}^{2+}$ mobilizers (our unpublished observations). Astrocyte cultures were grown to $80-90 \%$ confluency (typically 7-10 d), and microglia were removed by vigorously shaking the flasks at room temperature $(2-4 \mathrm{~h})$ on an orbital shaker. Cells were then grown to confluence in $35 \mathrm{~mm}$ culture dishes which were used 
for all experiments. Immunocytochemical analyses of our cultures have indicated that $<5 \%$ of plated cells at confluence are microglia (unpublished observations).

Detailed methods for harvesting and maintaining mixed embryonic (E18) hippocampal cultures have been described previously (Porter et al., 1997; Norris et al., 2002, 2006, 2008; Sama et al., 2008). Briefly, these cultures, which are composed of $85-90 \%$ neurons and astrocytes (in approximately equal numbers) were plated on poly-L-lysine-coated 35 $\mathrm{mm}$ dishes $\left(\sim 4 \times 10^{5}\right.$ cells $\left./ \mathrm{ml}\right)$ with $10 \%$ fetal bovine and $10 \%$ horse sera. At $3 \mathrm{~d}$ in vitro (DIV), culture media was supplemented with 5-fluoro-2-deoxy-uridine $(15 \mu \mathrm{g} / \mathrm{ml})$ to inhibit proliferation of nonneuronal cells. Cell death assays and glutamate measurements were conducted at $\sim 35$ DIV. Immunocytochemical labeling of cell type-specific markers indicate that cultures at this DIV typically contain a slightly greater balance of astrocytes and $<10 \%$ microglia, due to progressive neuronal death and dilution of fluoro-2-deoxy-uridine after periodic supplements of sera.

Preparation of amyloid- $\beta$ fragments. Synthetic $\mathrm{A} \beta_{(1-42)}$ (from rPeptide) dissolved in DMSO $(100 \mu \mathrm{g} / \mathrm{ml})$ was added to sodium phosphate buffer (50 mM NaPi, $150 \mathrm{~mm} \mathrm{NaCl}, \mathrm{pH} 7.5)$ at a final concentration of 2 $\mu \mathrm{g} / \mathrm{ml}$ and incubated at room temperature for $\sim 2 \mathrm{~h}$ to allow seeding and formation of peptide oligomers. The oligomerization process was stopped with the addition of $1 \% \mathrm{BSA}$. $\mathrm{A} \beta$ monomers were made by adding $1 \%$ BSA to a final concentration of $2 \mu \mathrm{g} / \mathrm{ml}$ synthetic $\mathrm{A} \beta_{(1-42)}$ in sodium phosphate buffer, directly from $-80^{\circ} \mathrm{C}$, followed by $2 \mathrm{~h}$ incubation at room temperature. One milliliter of preparation was loaded onto a G-75 column and run in MEM $+2 \mathrm{mg} / \mathrm{ml} \mathrm{BSA}$, and $1 \mathrm{ml}$ fractions were collected and peptide concentrations determined by sandwich ELISA as described previously (LeVine, 2004). For fibrillar $\mathrm{A} \beta, 30 \mu \mathrm{g} / \mathrm{ml} \mathrm{A} \beta_{(1-42)}$ in sodium phosphate buffer was placed at $37^{\circ} \mathrm{C}$ for $3 \mathrm{~d}$. Solution was sonicated using a probe sonicator and returned to $37^{\circ} \mathrm{C}$ for an additional 7 d. One milliliter preparations were loaded onto a G-75 Sephadex column and run in either MEM (for astrocyte cultures) or SMEM (for mixed cultures), followed by which $1 \mathrm{ml}$ fractions were collected and peptide concentrations determined by sandwich ELISA as described previously (LeVine, 2004). The fibrils formed were then stored at $-20^{\circ} \mathrm{C}$ until use. More than $95 \%$ of the fibrillar $A \beta$ was sedimentable at $16,000 \times$ $g$ and the resultant fibrils were Thioflavin T-positive (LeVine, 1999). Working concentration for all experiments was $\sim 65-75 \mathrm{nM}$.

Immunohistochemistry. Immunofluorescent labeling of GFAP, NFAT1, and NFAT3 was performed on formalin-fixed paraffin-embedded postmortem tissue from two control cases, two MCI cases, and three AD cases. Anatomically matched transverse hippocampal sections $(10 \mu \mathrm{m})$ were deparaffinized, rehydrated, and washed before antigen retrieval, which consisted of a heating procedure for GFAP and NFAT1 (Diva Decloaking solution from Biocare Medical) and protease digestion for NFAT3. After antigen retrieval, endogenous peroxidase activity was quenched with $0.3 \% \mathrm{H}_{2} \mathrm{O}_{2}$ in $100 \%$ methanol (30 $\mathrm{min}$ at room temperature). Slidemounted sections were first blocked for $20 \mathrm{~min}$ at room temperature with blocking buffer [Tris buffer saline (TBS) containing 4\% bovine serum albumin and 5\% normal goat serum] and then incubated for $48 \mathrm{~h}$ at $4^{\circ} \mathrm{C}$ with a mixture of the primary antibodies, 1:250 mouse monoclonal anti-GFAP (Cell Signaling Technology Inc) or 1:500 rat anti-GFAP (Invitrogen), and 1:125 anti-NFAT1 or anti-NFAT3 (Abcam) in blocking buffer. Slides were washed twice with TBS-T (TBS and $0.1 \%$ Tween 20) and incubated for $2 \mathrm{~h}$ at room temperature with the appropriate Alexa Fluor secondary antibodies (1:500, Invitrogen; Eugene, OR) diluted in blocking buffer. After rinsing twice with TBS-T, sections were dehydrated via a series of ethanol washes followed by incubation for $1 \mathrm{~h}$ in $70 \%$ ethanol containing $0.1 \%$ Sudan black to quench nonspecific fluorescence. The slides were then rinsed in $100 \%$ xylene and coverslipped with Prolong gold anti-fading mounting reagent (Invitrogen). Cell fluorescence was imaged with an inverted epifluorescence confocal microscope (DMIRE-2, Leica).

Replication-deficient adenovirus. Adenovirus encoding an NFATdependent luciferase reporter construct (Ad-NFAT-Luc), which encodes nine copies of an NFAT binding site (from the IL-4 promoter) and an additional minimal promoter upstream of a luciferase sequence, was kindly provided by Dr. Jeff Molkentin (University of Cincinnati, Cincin- nati, $\mathrm{OH}$ ) and has been described in detail previously (Wilkins et al., 2004). Adenovirus encoding the potent NFAT inhibitor, VIVIT (AdCMV-VIVIT-EGFP), and the control construct, $\beta$-galactosidase (AdCMV-LacZ-GFP, a kind gift from Dr. Rita Balice-Gordon, University of Pennsylvania, Philadelphia, PA) have also been previously described (Norris et al., 2008; Sama et al., 2008). The $2.2 \mathrm{kB}$ human Gfa2 promoter was kindly provided by Dr. Michael Brenner at the University of Alabama, Birmingham. This promoter, which guides astrocyte-specific expression of transgenes (Lee et al., 2008), was subcloned into an adenoviral shuttle vector (pAdlink, from the University of Pennsylvania) upstream from cDNA for either VIVIT-EGFP or EGFP alone. The resulting plasmids were then recombined with wild-type adenovirus to produce Ad-Gfa2-VIVIT-EGFP and Ad-Gfa2-EGFP (control virus). Viruses were titerd using the Adeno-X Rapid Titer kit (Clontech) and added to cultures at a multiplicity of infection (MOI) of 50.

NFAT-luciferase reporter assays. NFAT-luciferase reporter assays were performed as described previously (Sama et al., 2008). In brief, at $\sim 20 \mathrm{~h}$ before treatment with $\mathrm{A} \beta$ peptides, confluent astrocyte cultures were infected with Ad-NFAT-Luc. Cultures were also coinfected with control adenovirus (Ad-LacZ-GFP) or Ad-CMV-VIVIT-EGFP. After $24 \mathrm{~h}$ treatment with $\mathrm{A} \beta$ peptides, cultures were homogenized, pelleted, then resuspended in CAT buffer (250 mM Tris, pH 8.0, 1 mm EDTA) and stored at $-20^{\circ} \mathrm{C}$ until use. Typically, six dishes were analyzed per treatment group and all sample volumes were normalized to the same protein concentration using the Lowry method. Luciferase expression was quantified using a luciferase detection kit (Tropix) and plate reader.

NFAT-EGFP translocation. The pHA-NFAT1 (1-460)-GFP vector was kindly provided by Dr. Anjana Rao and has been described previously (Aramburu et al., 1999). This vector encodes the first 460 aa of the mouse NFAT1 isoform fused to EGFP and driven by a CMV promoter. Astrocyte cultures were transfected with pHA-NFAT1 (1-460)-GFP using Lipofectamine LTX and PLUS transfection reagents (Invitrogen). At $24 \mathrm{~h}$ after transfection, culture dishes were transferred to the stage of a Nikon E600 microscope, and EGFP expression was detected with appropriate filters using a $40 \times$ Fluor objective. After treatment with oligomeric A $\beta$, cells were imaged once every 5 min for 15 min using a Nikon CoolSnap ES digital camera. The average pixel intensity sampled from geometrically equivalent regions of interests in nuclear and cytosolic regions of individual astrocytes was calculated using MetaMorph 6 software (Molecular Devices).

Measurement of extracellular glutamate. A modified version of the UV method, described by Lund (1986), was used to estimate extracellular glutamate levels (Sama et al., 2008). Mixed astrocyte and neuronal cultures were treated with Gfa2 viruses and oligomeric $A \beta$ as described below for neuronal death assays. At $24 \mathrm{~h}$ after $\mathrm{A} \beta$ treatment, conditioned medium was harvested from each culture and spun down at 13,000 rpm to remove cellular debris. Supernatant $(250 \mu \mathrm{l})$ was transferred to a disposable cuvette and combined with reaction buffer (final volume of 2 $\mathrm{ml}$ ) consisting of $1.6 \%$ hydrazine monohydrate, $50 \mathrm{~mm}$ Tris, $1 \mathrm{~mm}$ EDTA, $0.5 \mathrm{~mm}$ adenosine $5^{\prime}$-diphosphate, and $1.5 \mathrm{~mm}$ NAD (all chemicals from Sigma). L-Glutamate in each sample was converted to $\alpha$-ketoglutarate via the addition of $30 \mu \mathrm{l}$ of glutamate dehydrogenase (1.2 kU/ml from Calzyme Laboratories). The corresponding proportional conversion of $\mathrm{NAD}^{+}$to $\mathrm{NADH}$ was measured 45 min later using a spectrophotometer. For each sample, absorbance was read at $340 \mathrm{~nm}$, and relative glutamate levels were determined from a standard curve of known glutamate concentrations.

Neuronal death assay. Five-week-old mixed cultures (astrocyte/neuronal) were infected with Gfa2-EGFP or Gfa2-VIVIT-EGFP (50 MOI, see above) for $\sim 6 \mathrm{~h}$ before further treatment with oligomeric $A \beta$ peptides. Final treatment conditions were: Ad-Gfa2-EGFP alone, Ad-Gfa2-VIVITEGPF alone, Ad-Gfa2-EGFP $\pm \mathrm{A} \beta$, and Gfa2-VIVIT-EGFP $\pm \mathrm{A} \beta$. Cells were incubated in $35 \mathrm{~mm}$ culture dishes for $48 \mathrm{~h}$ before neuronal cell death was assessed using the Live/Dead Cell Toxicity Assay (Invitrogen). Cells incorporating ethidium homodimer-1 (i.e., dead cells) were identified using fluorescence microscopy (E600 Nikon with appropriate filters). Putative neurons were then identified under phase contrast based on their distinctive morphology and the size of their soma. Moreover, virally infected astrocytes could be identified by expression of an EGFP 
marker. Rarely, did EGFP-containing cells incorporate ethidium homodimer and these were not included in analysis. The number of dead neurons was counted in 10 separate, randomly chosen $10 \times$ fields within each condition ( $n=10$ fields per condition). Field averages were compared across conditions using ANOVA (see below). Experiments were repeated in three separate sister cultures.

Statistical analyses. The percentage of protein associated with the nuclear fraction in a given subject was calculated by taking the ratio of nuclear protein levels to total (cytosolic + nuclear) protein levels and multiplying by 100 . Unless otherwise indicated, data for each patient category is shown as the mean plus the SD from the mean. Significant effects of patient category (for postmortem studies), and $\mathrm{A} \beta$ treatment (cell culture studies) were determined using ANOVA. Changes in the nuclear/ cytosolic ratio of NFAT-EGFP in primary astrocytes were determined using repeatedmeasures ANOVA. Significant correlations $(p<0.05)$ between CN/NFAT signaling constituents, $A \beta$ and MMSEs were determined using simple regression analysis. Statistically significant omnibus ANOVAs $(p<0.05)$ were followed by Fischer's PLSD post hoc tests to identify specific pairwise differences.

\section{Results}

Selective changes in the subcellular localization of NFAT isoforms with AD NFATs are a family of transcription factors under the direct control of the $\mathrm{Ca}^{2+}$ dependent protein phosphatase $\mathrm{CN}$ (Hogan et al., 2003). When dephosphorylated by $\mathrm{CN}$, these transcription factors leave the cytosol and preferentially associate with nuclear compartments to regulate gene expression. To investigate possible changes in the activational state of the CN/NFAT pathway with the progression of $\mathrm{AD}$, we prepared cytosolic and nuclear fractions from postmortem human hippocampal tissue of $\mathrm{AD}, \mathrm{MCI}$, and control subjects (Table 1) and measured NFAT protein levels using Western blot analysis (Fig. 1A). Multiple NFAT isoforms (i.e., NFATs 1, 2, and 3) were investigated because each has been shown to exhibit unique contributions to a variety of cellular processes in peripheral tissues (Crabtree and Olson, 2002; Horsley and Pavlath, 2002). Subcellular distribution of NFATs in cerebellum, which is relatively more resistant to the development of $\mathrm{AD}$ pathology, was also investigated (Fig. $1 B$ ).

In hippocampus, total protein levels for each NFAT isoform (measured in the combined cytosolic and nuclear fractions) exhibited high intragroup variability and no significant differences were observed, except for the NFAT3 isoform, which was reduced in the $\mathrm{AD}$ group ( $p<0.04$ vs controls, data not shown). In contrast, the percentage of total NFAT protein associated with hippocampal nuclear fractions (nuc-NFAT) increased as a function of disease state (Fig. 1C-E). For NFAT1, this increase occurred with $\mathrm{MCI}$ ( $p<0.05$ vs controls), but not with AD. In fact,

I
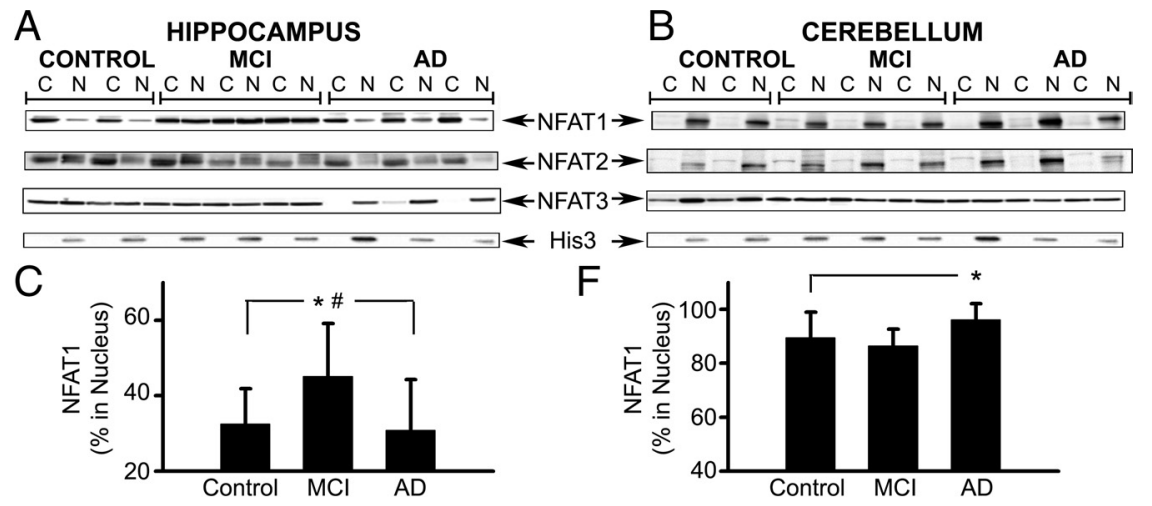

$\mathrm{F}$
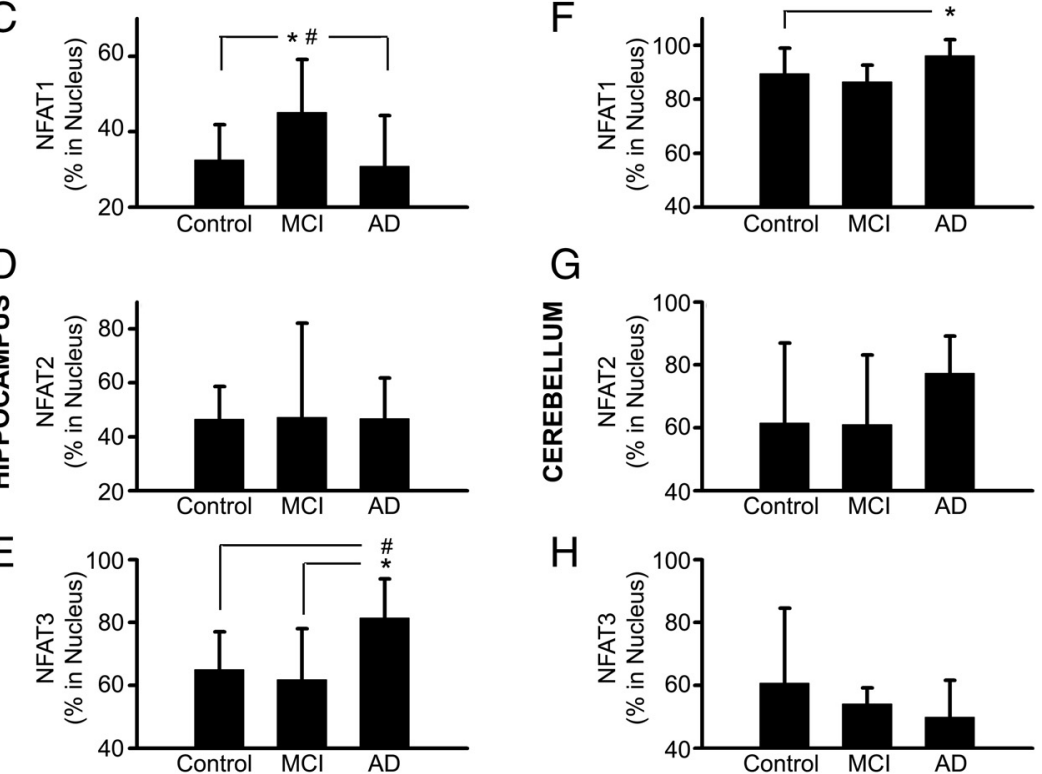

$\mathrm{H}$

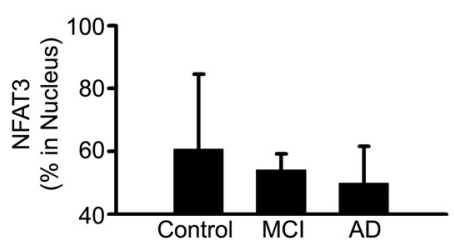

$J$

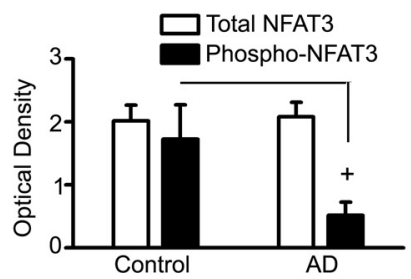

Figure 1. Isoform- and region-specific changes in the nuclear accumulation of NFATs with MCI and AD. $\boldsymbol{A}, \boldsymbol{B}$, Representative Western blots for NFATs 1, 2, and 3 in cytosolic (C) and nuclear (N) fractions prepared from hippocampal (A) and cerebellar (B) tissue samples from control, MCl, and AD patients. Histone-3 (His-3) levels were also probed to confirm the purity of nuclear fractions. ote that blots for each protein were derived from different gels. $\mathbf{C}-\boldsymbol{H}$, Percentage of NFAT1, 2, and 3 protein levels (mean \pm SD) wippocampal $(\boldsymbol{C} \boldsymbol{E})$ and cerebellar $(\boldsymbol{F}-\boldsymbol{H})$ nuclear fractions from control, $\mathrm{MCl}$, and AD subjects. The results revealed 作 ( $)$ was increased, whereas NFAT3 $(\boldsymbol{H})$ was decreased with AD. I, Western blot of immunoprecipitated NFAT3 from whole ( Mean \pm SD band intensity (optical density in arbitrary units) of total NFAT3 and phospho-NFAT3 from subjects shown in $I$. Results showed that the increased nuclear localization of NFAT3 in AD patients is associated with reduced NFAT3 phosphorylation levels. ${ }^{*} p<0.05,{ }^{\#} p<0.01,{ }^{+} p<0.001$.

nuc-NFAT1 showed a small decrease in $\mathrm{AD}$ subjects relative to controls. Nearly the opposite pattern was found for nuc-NFAT3, which was slightly reduced in MCI subjects, but markedly increased in the $\operatorname{AD}$ group $(p<0.01$ and $p<0.001$ vs control and MCI, respectively). No changes in nuc-NFAT2 were observed in the hippocampus.

NFAT localization patterns were markedly different in cerebellar tissue (Fig. 1B,F-H). Generally, nuc-NFAT1 levels (Fig. $1 F$ ) were much higher in the cerebellum relative to the hippocampus, regardless of pathological state. Moreover, nucNFAT1 levels were slightly, but significantly, elevated in AD relative to control cases $(p<0.05)$. No significant differences were observed for NFAT2 (Fig. $1 G$ ) and NFAT3 (Fig. $1 H$ ) in the cerebellum, although nuc-NFAT2 levels tended to be elevated with $\mathrm{AD}$, whereas nuc-NFAT3 levels tended to be decreased with AD. Together, these results reveal isoform and brain region- 
A HIPPOCAMPUS

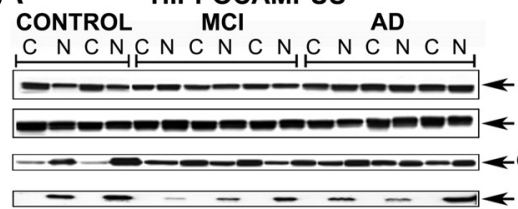

C
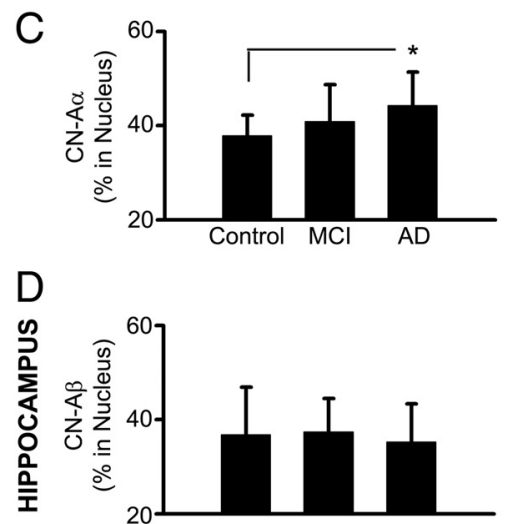

E

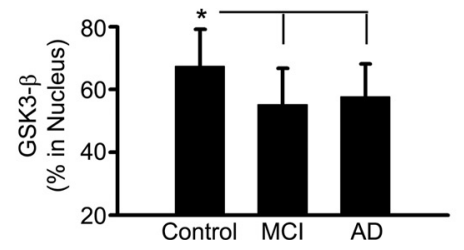

B CONTROL CEREBELLUM

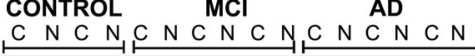

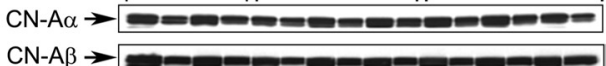

$\leftarrow$ GSK3- $\beta \rightarrow-\ldots \ldots$

\section{$\mathrm{F}$}

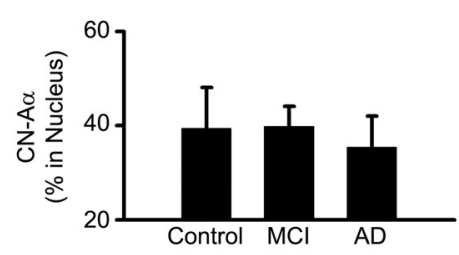

G

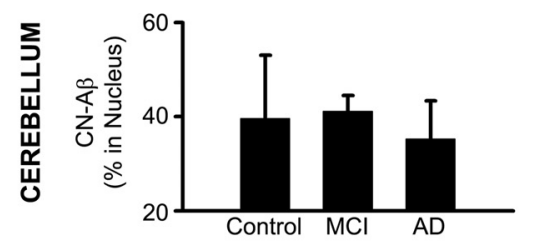

$\mathrm{H}$

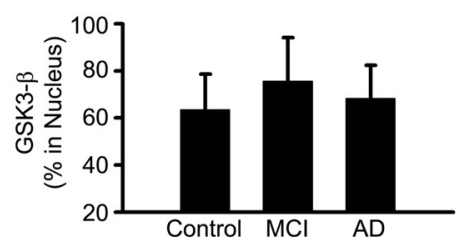

Figure 2. Isoform- and region-specific changes in the nuclear accumulation of CN and GSK3- $\beta$ with MCl and AD. $\boldsymbol{A}, \boldsymbol{B}$, Representative Western blots for $\mathrm{CN}-\mathrm{A} \alpha, \mathrm{CN}-\mathrm{A} \beta$, and GSK3- $\beta$ in cytosolic $(\mathrm{C})$ and nuclear (N) fractions prepared from hippocampal $(\boldsymbol{A})$ and cerebellar $(\boldsymbol{B})$ tissue samples from control, $\mathrm{MCl}$, and $\mathrm{AD}$ patients. Histone-3 (His-3) levels were also probed to confirm the purity of nuclear fractions. Note that blots for each protein were derived from different gels. $\boldsymbol{C}-\boldsymbol{H}$, Percentage of $\mathrm{CN}-\mathrm{A} \alpha, \mathrm{CN}-\mathrm{A} \beta$, and GSK3- $\beta$ protein levels (mean \pm SD) associated with hippocampal $(\boldsymbol{C}-\boldsymbol{E})$ and cerebellar $(\boldsymbol{F}-\boldsymbol{H})$ nuclear fractions from control, $\mathrm{MCl}$, and $A D$ subjects. The results revealed an increase in the association of $\mathrm{CN}-\mathrm{A} \alpha(\boldsymbol{C})$ with hippocampal nuclear fractions with $A D$. Conversely, the nuclear accumulation of GSK3- $\beta(\boldsymbol{E})$ was reduced in the hippocampus with $\mathrm{MCl}$ and $A D$. No significant changes in $\mathrm{CN}-\mathrm{A} \alpha, \mathrm{CN}-\mathrm{A} \beta$, or GSK3- $\beta$ were observed in the cerebellum. ${ }^{*} p<0.05$.

A
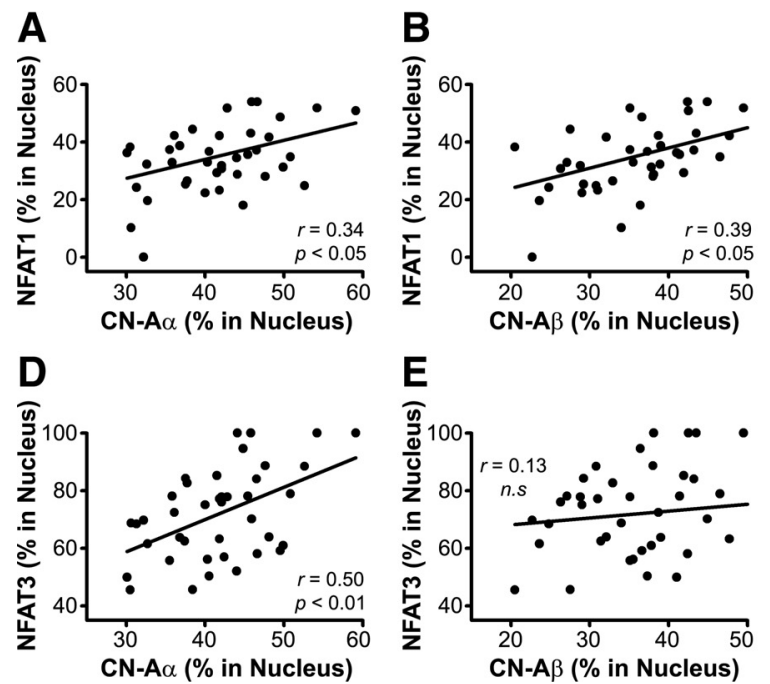

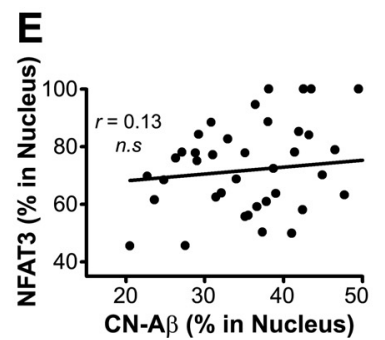

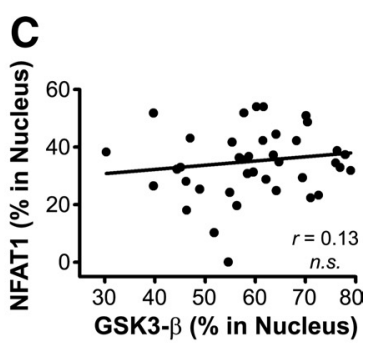

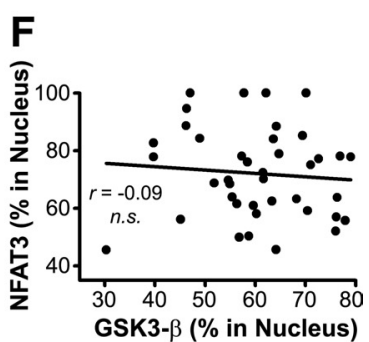

Figure 3. Interrelationships among NFATs, CN, and GSK3- $\beta$ in hippocampus. Scatter plots illustrate hippocampal nuclear levels (percent in nucleus) for NFAT1 $(\boldsymbol{A}-\boldsymbol{C})$ and NFAT3 $(\boldsymbol{D}-\boldsymbol{F})$ plotted against nuclear levels for CN-A $\alpha(\boldsymbol{A}, \boldsymbol{D}), \mathrm{CN}-\mathrm{A} \beta$ $(\boldsymbol{B}, \boldsymbol{E})$, and GSK3- $\beta(\boldsymbol{C}, \boldsymbol{F})$ within the same subjects regardless of disease state. Plots were fitted using simple regression analysis. Note that the nuclear accumulation of both NFATs 1 and 3 is directly proportional to nuclear CN-A $\alpha$ levels $(\boldsymbol{A}, \boldsymbol{D})$. Conversely, NFAT1, but not NFAT3, also showed a direct correlation to $C N-A \beta(B)$. Neither NFAT isoform showed a significant correlation to GSK3- $\beta$. n.S., Not significant.

specific changes in NFAT localization. The differential accumulation of NFAT1 and NFAT3 in hippocampal nuclear fractions of $\mathrm{MCI}$ and $\mathrm{AD}$ patients suggests that these isoforms may preferentially contribute to the different stages of $\mathrm{AD}$.

To validate the observation that elevated nuc-NFAT levels in hippocampus corresponded to changes in the activational state of NFATs, we measured phospho-NFAT3 levels in whole hippocampal homogenates prepared from eight control subjects with the lowest nuc-NFAT3 levels and eight AD subjects with the highest nuc-NFAT3 levels. As shown in Figure 1 I, NFAT3 was immunoprecipitated and subjected to Western blot using an anti-NFAT3 antibody to label total NFAT3 and an antiphosphoserine antibody to label phosphoNFAT3. The results demonstrated a nearly $70 \%$ reduction in phospho-NFAT3 levels in the $\mathrm{AD}$ group relative to controls $(p<$ 0.001 ) (Fig. 1J), consistent with increased $\mathrm{CN}$-mediated dephosphorylation in the hippocampus.

\section{Interrelationships among NFAT} isoforms, $\mathrm{CN}$, and GSK3- $\beta$

Whereas the translocation of NFATs from the cytosol to the nucleus is directly governed by $\mathrm{CN}$ activity, the rephosphorylation and subsequent export of NFATs from the nucleus is mediated by several kinases. One such kinase, GSK3- $\beta$, has been shown to contribute significantly to the regulation of NFAT transcriptional activity in hippocampal tissue (Graef et al., 1999). However, interactions between GSK3- $\beta$ and NFATs in nuclear compartments may be countered or negated by $\mathrm{CN}$, which can also translocate to the nucleus of neural cells, especially under degenerative conditions (Shioda et al., 2007). The relative distribution of $\mathrm{CN}$ and GSK3- $\beta$ across cytosolic and nuclear compartments may therefore contribute to changes in the subcellular localization of NFATs with AD. To test for this possibility, we measured protein levels for the two major $\mathrm{CN}-\mathrm{A}$ isoforms $(\mathrm{CN}-\mathrm{A} \alpha$ and $\mathrm{CN}-\mathrm{A} \beta$ ) and GSK3- $\beta$ in the same cytosolic and nuclear fractions used in Figure 1. Representative Western blots are shown in Figure 2, $A$ and $B$, respectively.

In hippocampus, total protein levels for $\mathrm{CN}-\mathrm{A} \alpha$ and $\mathrm{CN}-\mathrm{A} \beta$ did not change as a function of disease state, whereas total GSK3- $\beta$ levels were elevated with $A D$ (data not shown). As shown in Figure 2, $C$ and $E$, the percentage of $\mathrm{CN}-\mathrm{A} \alpha$ and GSK3- $\beta$ associated with the nuclear fraction (i.e., nuc-CN-A $\alpha$ and nuc-GSK3- $\beta$ ) 
changed in opposite directions as a function of disease state. Nuc- $\mathrm{CN}-\mathrm{A} \alpha$, was slightly increased in both MCI and AD subjects, although only the $\mathrm{AD}$ group showed a significant increase $(p<0.05)$ compared with age-matched controls (Fig. $2 A, C$ ). In contrast, nuc-GSK3- $\beta$ exhibited a significant decrease in both MCI $(p<0.05)$ and $\mathrm{AD}(p<0.05)$ subjects compared with the age-matched controls (Fig. 2E). No significant differences in nuc- $\mathrm{CN}-\mathrm{A} \beta$ were observed in hippocampus (Fig. 2D).

In cerebellum, total protein levels for $\mathrm{CN}-\mathrm{A} \alpha$ and GSK3- $\beta$ did not change as a function of disease state. Total $\mathrm{CN}-\mathrm{A} \beta$ levels, however, did show a significant reduction with $\mathrm{AD}(p<0.05$, data not shown). As with NFATs, changes in the subcellular distribution of $\mathrm{CN}$ isoforms and GSK3- $\beta$ in the cerebellum tended to occur in opposite directions relative to the hippocampus. That is, nuc- $\mathrm{CN}-\mathrm{A} \alpha$ and nuc-CN-A $\beta$ showed an overall decrease in $\mathrm{MCI}$ and $\mathrm{AD}$ patients, and nucGSK3- $\beta$ showed an increase in MCI (Fig. $2 \mathrm{~F}-\mathrm{H})$. However, none of these changes reached significance.

Elevations in the nuclear localization of NFATs 1 and 3 in the hippocampus as a function of disease state (Fig. 1C,E) appear to correspond to increased nuc$\mathrm{CN}-\mathrm{A} \alpha$ levels and/or to decreased nucGSK3- $\beta$ levels (Fig. $2 C, E$ ). To investigate these interrelationships more directly, we performed within-subject correlational analyses on hippocampal cellular fractions (Fig. 3). It was predicted that nuc-NFAT levels would show a positive correlation with nuc-CN isoforms and an inverse correlation with nuc-GSK3- $\beta$. However, although NFATs directly correlated to the subcellular localization of $\mathrm{CN}$ (Fig. $3 A, B, D$ ), no significant correlations to GSK3- $\beta$ were revealed (Fig. $3 C, F$ ). Greater nuc-CN-A $\alpha$ levels were directly proportional to increases in both nuc-NFAT1 (Fig. $3 A$ ) and nuc-NFAT3 (Fig. 3D). Conversely, nuc-CN-A $\beta$ was correlated to nuc-NFAT1 (Fig. 3B) but not to nuc-NFAT3 (Fig. 3E). These selective correlations suggest that $\mathrm{CN}$ and NFATs may interact in an isoform-specific manner during different stages of $\mathrm{AD}$.

Similar correlational analyses were performed on cerebellar tissue and also revealed isoform-specific interactions between $\mathrm{CN}$ and NFATs (see supplemental Fig. 1). However, these correlations differed markedly from those observed in hippocampus. Specifically, nuc-NFAT3 exhibited a preferential correlation to nuc-CN-A $\beta(r=0.56, p<0.01)$ (supplemental Fig. $1 E$, available at www.jneurosci.org as supplemental material), rather than nuc-CN-A $\alpha$. In further contrast to the hippocampus, nucNFAT3 was inversely correlated to nuc-GSK3- $\beta$ in cerebellum $(r=-0.35, p<0.05)$ (supplemental Fig. $1 F$, available at www. jneurosci.org as supplemental material).
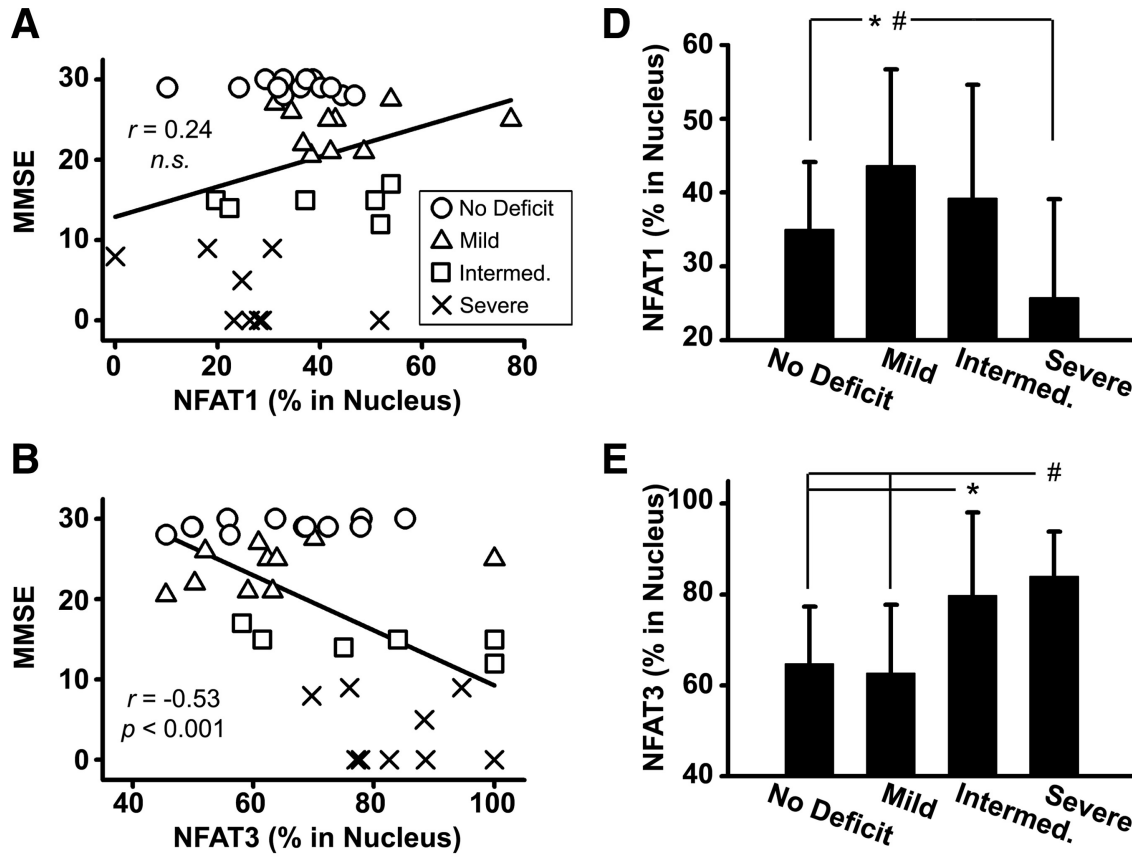

$E$
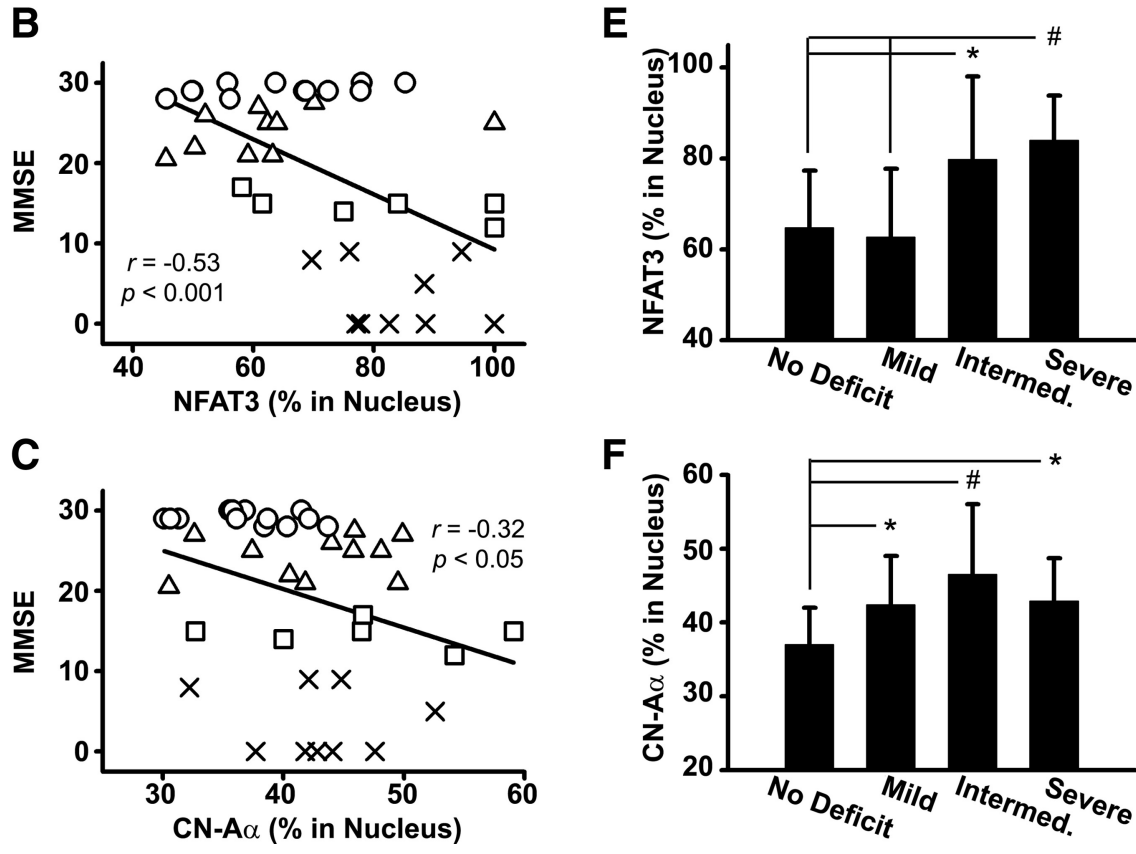

Figure 4. Selective changes in hippocampal CN/NFAT is oforms as cognitive deficits emerge. $\boldsymbol{A}-\boldsymbol{C}$, Scatter plots illustrate MMSE cores plotted against nuclear levels (percent in nucleus) for NFAT1 (A), NFAT3 (B), and CN-A $\alpha(\boldsymbol{C})$. D $-\boldsymbol{F}$, Percentage (mean \pm SD) 作 (D). The precipitous decrease in NFAT1 levels between the mild and severe deficit stages likely accounts for the positive (albeit the mildest stages of cognitive decline $(\boldsymbol{F})$. However, like NFAT 3, nuclear $\mathrm{CN}-\mathrm{A} \alpha$ levels continued to increase as cognition worsened. ${ }^{*} p<0.05,{ }^{*} p<0.01$.

Selective changes in hippocampal CN/NFAT isoforms as cognitive deficits emerge

Several reports have linked the dysregulation of CN signaling to impaired cognitive function in animal models of aging and AD (Foster et al., 2001; Genoux et al., 2002; Dineley et al., 2007). We therefore performed within-subject correlational analyses to determine whether changes in the hippocampal CN/NFAT pathway (Figs. 1, 2) correspond to cognitive decline as assessed by the Mini Mental State Examination [MMSE] (Fig. 4A-C). We also recategorized control, MCI, and $\mathrm{AD}$ subjects into four groups based on cognitive status: no deficit (MMSE $=28-30, n=15)$, mild (MMSE $=20-27, n=$ 11 ), intermediate (MMSE $=12-19, n=6$ ), and severe deficit (MMSE $=0-11, n=9)$. The nuclear accumulation of $\mathrm{CN}$ and NFAT proteins were then compared across these groups (Fig. $4 D-F)$ to pinpoint when changes in CN/NFAT signaling emerge during the progression of dementia. 

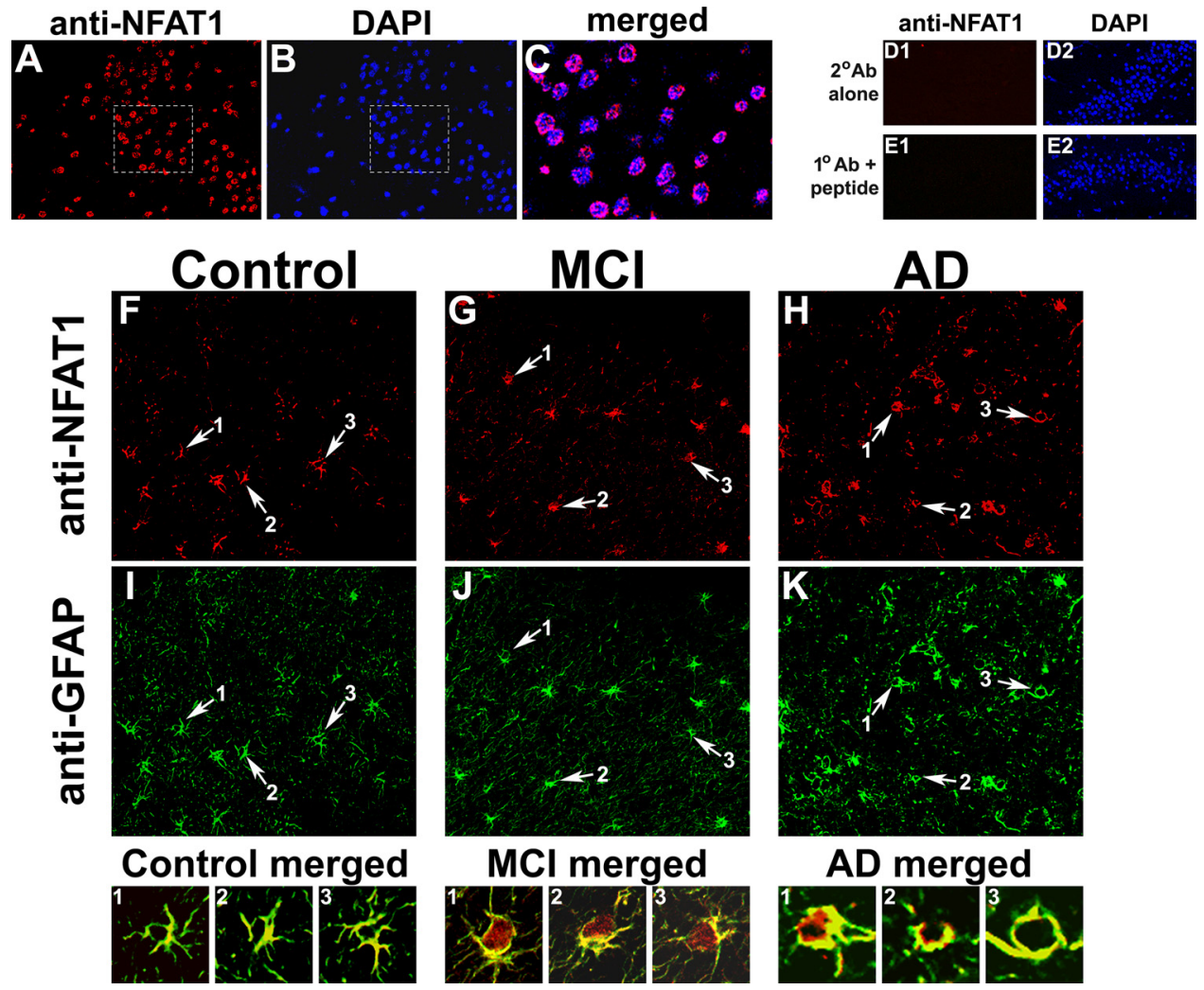

Figure 5. NFAT1 is expressed in neurons and astrocytes in postmortem human hippocampal tissue. $A, B$, Confocal immunofluorescent images of dentate gyrus from human AD hippocampal sections showing double labeling for NFAT1 (red) $(\boldsymbol{A})$ and DAPI counterstain (blue) ( $\boldsymbol{B})$. $\boldsymbol{C}$, Merged image of the highlighted areas from $\boldsymbol{A}$ and $\boldsymbol{B}$. The ring-like expression pattern suggests that NFAT1 is primarily distributed in the cytosol of the neurons. $\boldsymbol{D}, \boldsymbol{E}$, Micrographs of the human dentate gyrus (AD case) show DAPI labeling throughout the neuronal cell body layer, but little to no red fluorescence when secondary antibody is used alone (D1), or when NFAT1 primary antibody is coadministered with an NFAT1 blocking peptide $(\boldsymbol{E} \boldsymbol{E})$. $\boldsymbol{F}-\boldsymbol{K}$, Colabeling of representative control $(\boldsymbol{F}, \boldsymbol{I})$, $\mathrm{MCI}(\boldsymbol{G}, \boldsymbol{J})$, and AD $(\boldsymbol{H}, \boldsymbol{K})$ sections using antibodies to NFAT1 $(\boldsymbol{F}-\boldsymbol{H})$ and to GFAP $(\boldsymbol{I}-\boldsymbol{K})$ for identification of astrocytes. In each panel, arrows point to regions that illustrate colocalization of NFAT1 and GFAP (numbered 1-3), and are provided as high-magnification merged images in the corresponding panels below. Note that NFAT1 is present in both neurons and astrocytes but its localization at the cellular level appears to vary as a function of pathology. Specifically, NFAT1 tends to show greater nuclear accumulation in astrocytes with MCI.

Nuc-NFAT1 levels showed a direct, albeit insignificant, correlation with MMSE scores (Fig. 4A), suggesting that cognition improves as NFAT1 accumulates in the nucleus. This relationship appears at odds with the results in Figure $1 C$, which show an increase in nuc-NFAT1 in MCI cases. However, closer inspection of protein levels across subjects sorted by cognitive status (Fig. $4 D)$, confirmed that nuc-NFAT1 increases during the earliest stages of dementia ( $p=0.05$, mild vs no deficit). This increase was then followed by a precipitous decrease as cognitive decline progressed ( $p<0.05$, severe vs mild and intermediate groups), which likely accounts for the slightly positive correlation between nuc-NFAT1 and MMSE scores (Fig. 4A). In contrast to NFAT1, nuc-NFAT3 levels exhibited a relatively strong, inverse correlation to cognitive status $(r=-0.52, p<0.001)$ (Fig. $4 B$ ). Moreover, nuc-NFAT3 levels exhibited a nearly opposite pattern of change across the progressing stages of cognitive dysfunction (Fig. 4E). That is, nuc-NFAT3 levels showed a small drop in the mild deficit cases before increasing substantially in subjects with intermediate and severe deficits $(p<0.01$, severe vs no deficit and mild deficit).

The relationship between nuc-CN-A $\alpha$ and cognitive status exhibited a pattern that was similar to and different from NFATs 1 and 3. Similar to nuc-NFAT3, nuc-CN-A $\alpha$ was inversely correlated with cognitive status $(r=-0.32, p<0.05)$ (Fig. $4 C)$. Nuc$\mathrm{CN}-\mathrm{A} \alpha$ levels were also increased at the intermediate and severe stages of cognitive decline $(p<0.05$, intermediate and severe vs no deficit) (Fig. $4 F$ ). However, in contrast to NFAT3, and similar to NFAT1, the increase in nuc-CN-A $\alpha$ levels emerged in the mildest stages of cognitive dysfunction $(p<0.05$, mild vs no deficit). Although the results demonstrate that altered CN/NFAT signaling is strongly associated with cognitive decline, this association is complex, because it appears different NFAT isoforms are involved in, or activated at, different stages of dementia.

NFATs 1 and 3 are expressed in neurons and astrocytes in human hippocampal tissue

$\mathrm{CN}$ is easily detected in neurons of healthy brain tissue and has been well characterized for its abundant expression in cortical, striatal, and hippocampal neurons. In non-neuronal cell types, such as astrocytes, $\mathrm{CN}$ levels are usually much lower in healthy tissue. However, astrocytic $\mathrm{CN}$ expression can become much more prominent with aging, amyloid deposition, and/or neural injury (Hashimoto et al., 1998; Norris et al., 2005). Supplemental Figure 2 (available at www.jneurosci.org as supplemental material) shows $\mathrm{CN}-\mathrm{A} \alpha$ expression associated with amyloid deposits and astrocytes in human $\mathrm{AD}$ tissue. Several recent studies suggest that $\mathrm{CN}$ signaling in astrocytes plays an important role in neuroinflammation and glutamate dyshomeostasis (Fernandez et al., 2007; Canellada et al., 2008; Sama et al., 2008), both of which may negatively impact neuronal function and viability during the course of AD. These studies have further implicated NFATs as a primary target for $\mathrm{CN}$ signaling in astrocytes, yet little is known about astrocytic NFAT expression in healthy or diseased brain tissue. Figures 5 and 6 show confocal immunofluorescent images 


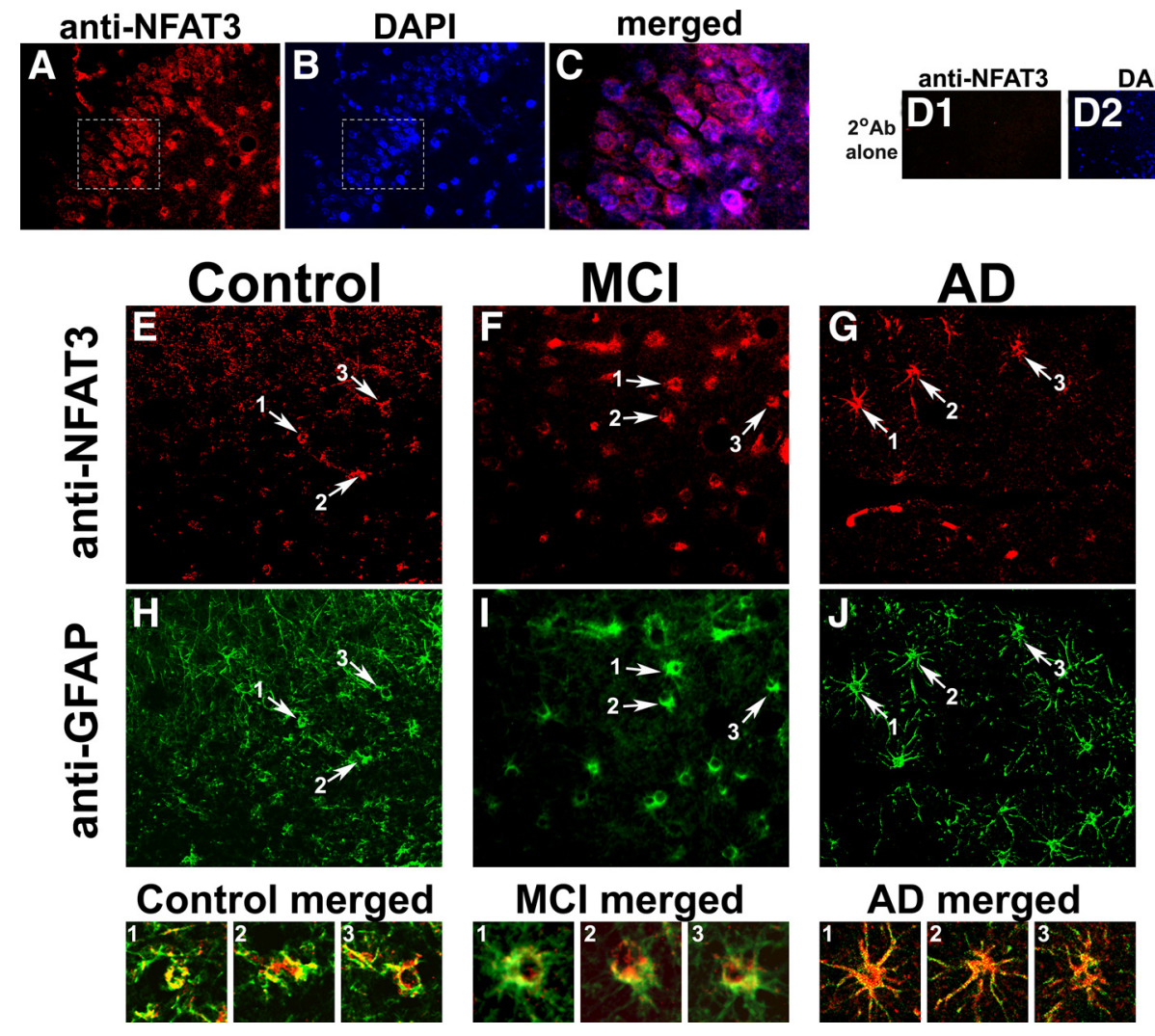

Figure 6. NFAT3 is expressed inneuronsandastrocytes in postmortem humanhippocampal tissue. $A, B$, Confocal immunofluorescentimages ofdentategyrusfrom human MCI hippocampussections showing double labeling for NFAT3 (red) (A) and DAPI counterstain (blue) (B). C, Merged image of the highlighted areas from $\boldsymbol{A}$ and $\boldsymbol{B}$. Results show that NFAT3 is primarily distributed in the cytosol of the neurons. $\boldsymbol{D}$, Micrographs of the human dentate gyrus (AD case) show DAPI labeling throughout the neuronal cell body layer (D2), but little to no red fluorescence when secondary antibody is used alone (D1). $\boldsymbol{E}-\boldsymbol{J}$, Colabeling of representative control $(\boldsymbol{E}, \boldsymbol{H}), \mathrm{MCI}(\boldsymbol{F}, \boldsymbol{I})$, and AD $(\boldsymbol{G}, \boldsymbol{J})$ sections using antibodies to NFAT3 $(\boldsymbol{E}-\boldsymbol{G})$ and to GFAP $(\boldsymbol{H}-\boldsymbol{J})$ for identification of astrocytes. In each panel, arrows point to regions that illustrate colocalization of NFAT3 and GFAP (numbered 1-3), and are provided as high-magnification, merged images in the corresponding panels below. Note that NFAT3 is present in both neurons and astrocytes but its localization at the cellular level appears to vary as a function of pathology. Specifically, NFAT3 tends to appear at higher levels throughout astrocytes with AD, and is most intensely expressed in the soma and nucleus.

of formalin-fixed parafin-embedded human hippocampal tissue sections labeled with antibodies to the astrocyte marker glial fibrillary acidic protein (GFAP), and also to NFATs 1 and 3. For some images, a 4',6'-diamidino-2-phenylindole dihydrochloride (DAPI) counter label is also provided to highlight well defined neuronal layers in the hippocampus.

Consistent with previous work showing NFAT expression in neurons in cell culture and intact animals (Graef et al., 1999; Shioda et al., 2007; Luoma and Zirpel, 2008; Nguyen and Di Giovanni, 2008), we observed strong NFAT1 labeling in human hippocampal neuronal layers (Fig. $5 A-C$ ). In most neurons, NFAT1 exhibited a "ring-like" expression pattern regardless of disease state (Fig. 5C), suggesting a primarily cytosolic distribution. As a negative control, some specimens were treated either with secondary antibody alone, or with NFAT1 primary antibody along with an NFAT1 blocking peptide. Figure $5, D$ and $E$, shows that negligible signal was detected under these conditions, confirming that antibody labeling was specific to endogenous NFAT1 expression. As shown in Figure $5 F-K$, NFAT1 also appeared in most astrocytes where its intracellular distribution was more variable compared with neurons. As with neurons, many astrocyte somata exhibited a ring-like expression pattern of NFAT1. However, NFAT1 also appeared in many astrocytic processes. In addition, NFAT1 was distributed evenly within many astrocytes, with no apparent exclusion from nuclear compartments. This pattern of labeling was especially notable in astrocytes in MCI sections (Fig. 5, MCI merged), consistent with Western blot results in Figure 1C.
Similar to NFAT1 expression, NFAT3 was detected in both neurons and astrocytes (Fig. $6 A-C$ ). Again, negative control conditions in which specimens were treated with secondary antibody alone, revealed little to no labeling (Fig. 6D). In neurons, NFAT3 was usually limited to somata and, like NFAT1, showed a characteristic ring-like distribution. No striking differences in neuronal expression were observed across disease state. In contrast to NFAT1, astrocytic NFAT3 labeling and putative nuclear localization was more apparent in $\mathrm{AD}$ tissue specimens (Fig. $6 E-J$ ). Indeed, numerous astrocytes in $\mathrm{AD}$ hippocampus showed strong labeling in processes as well as somata, although signal intensity was typically greater in the somatic/nuclear regions (see Fig. 6, $\mathrm{AD}$ merged), consistent with Western blot results in Figure $1 E$.

Increased CN/NFAT signaling is directly associated with elevated A $\beta$ levels

Previously, we reported that $\mathrm{CN}-\mathrm{A} \alpha$ expression in APP/PS1 mice is especially pronounced in astrocytes surrounding amyloid plaques (Norris et al., 2005) (see also supplemental Fig. 2, available at www.jneurosci.org as supplemental material). In addition, $\mathrm{A} \beta_{(1-42)}$ peptides, the primary constituents of amyloid plaques, have been shown to potently stimulate $\mathrm{CN}$-dependent signaling in cell culture models, brain slices, and intact animals (Chen et al., 2002; Norris et al., 2005; Shankar et al., 2007; Reese et al., 2008). Based on these findings, we sought to determine the extent to which changes in the nuclear accumulation of $\mathrm{CN}$ and NFATs is linked to amyloid pathology. Levels for soluble $\mathrm{A} \beta_{(1-42)}$ were measured in postmortem human hippocampal tissue by 
A
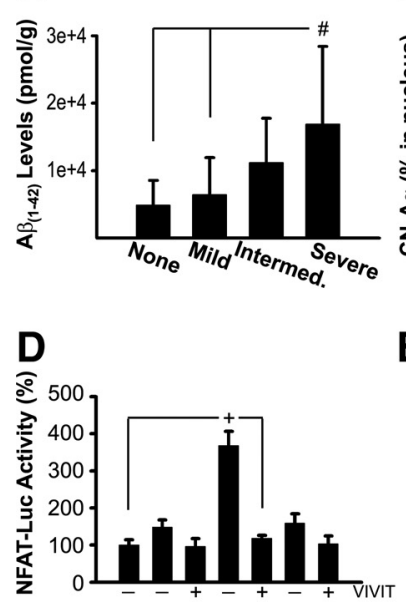

CT $\overline{\text { Mono }} \overline{\text { Oligo }} \overline{\text { Fibril }}$
B

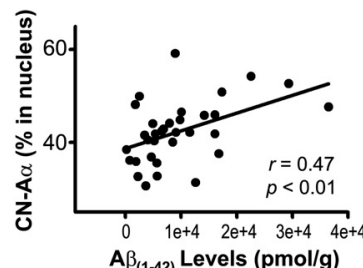

E

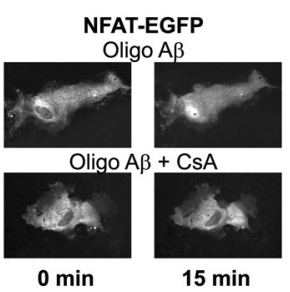

C

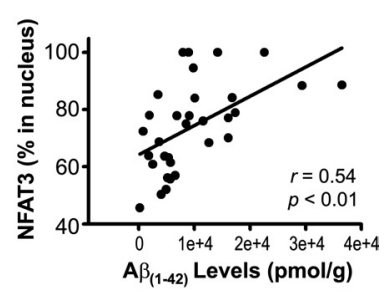

$\mathbf{F}$

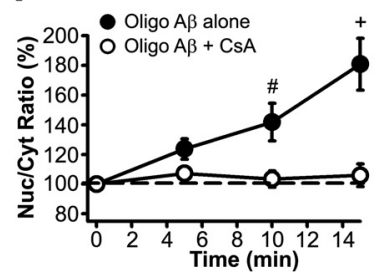

Figure 7. $A \beta$ levels are positively correlated to CN/NFAT signaling in postmortem hippocampus and directly activate NFAT transcriptional activity in primary astrocyte cultures. $A$, Soluble $A \beta_{(1-42)}$ levels (mean \pm SD) in whole hippocampal homogenates from subjects exhibiting different degrees of cognitive impairment [no deficit, $n=12$; mild, $n=11$; intermediate (Intermed.), $n=6$; and severe, $n=9$ ]. As expected, there was a steady increase in $A \beta_{(1-42)}$ levels as the severity of dementia progressed. $\boldsymbol{B}, \boldsymbol{C}$, Scatter plots illustrate nuclear levels (percent in nucleus) for CN-A $\alpha$ and NFAT3 plotted against soluble A $\beta_{(1-42)}$ levels, respectively. Nuclear accumulation of both CN-A $\alpha$ and NFAT3 in human hippocampus increased with increasing $A \beta_{(1-42)}$. D, Mean \pm SEM. NFAT-luciferase activity [\% control (CT)] in primary rat astrocyte cultures measured after $24 \mathrm{~h}$ application of monomeric (Mono), oligomeric (0ligo), or fibrillar (Fibril) $A \beta$ peptides $(65-75 \mathrm{~nm})$ in the presence $(+)$ or absence $(-)$ of the potent NFAT inhibitor VIVIT ( $n=6-8$ dishes per condition). Relative to monomeric and fibrillar A $\beta$, NFAT-luc activity was stimulated to a far greater extent by $A \beta$ oligomers. $\boldsymbol{E}$, Representative fluorescent images of NFAT-EGFP expression in individual astrocytes before and 15 min after treatment with oligomeric $A \beta$ in the presence or absence of the $C N$ inhibitor, cyclosporin $A(C s A, 5 \mu \mathrm{m})$. Redistribution of NFAT-EGFP from the cytosol to the nucleus occurred within minutes of $A \beta$ stimulation. $F$, Mean \pm SEM nuclear/cytosolic (Nuc/Cyt) ratio (percentage at zero time point) of NFAT-EGFP in astrocytes treated with oligomeric $A \beta$ alone $(n=19)$ or with CsA $(n=10)$. Results demonstrate a significant increase in the Nuc/cyt ratio of NFAT in astrocytes within 15 min after A $\beta$ treatment. No translocation was observed in cells pretreated with CsA. ${ }^{\#} p<0.01,{ }^{+} p<0.001$.

ELISA according to our previously published methods (Murphy et al., 2007). As expected, we observed a steady increase in soluble $\mathrm{A} \beta_{(1-42)}$ as the severity of dementia progressed (Fig. 7A). Moreover, soluble $A \beta_{(1-42)}$ levels in the hippocampus were strongly and positively correlated to the nuclear accumulation of both $\mathrm{CN}-\mathrm{A} \alpha$ and NFAT3 (but not CN-A $\beta$, or NFAT1) (Fig. $7 B, C$ ). These results suggest that changes in CN/NFAT signaling with dementia and $\mathrm{AD}$ may be driven, in part, by elevations in soluble $\mathrm{A} \beta_{(1-42)}$.

In addition to its direct effects on neuronal function and viability, $A \beta$ also directly and potently induces astrocyte activation and stimulates the production of numerous potentially neurotoxic factors (Akama et al., 1998; Akama and Van Eldik, 2000). Because CN and NFAT isoforms are present in astrocytes (Figs. 5, 6), and involved in the intracellular cascades leading to astrocyte activation (Norris et al., 2005; Sama et al., 2008), we next determined whether increased $A \beta$ levels directly stimulate CN/NFAT activity in a primary astrocyte culture model (Fig. $7 D-F$ ). Monomeric, oligomeric, and fibril $\mathrm{A} \beta_{(1-42)}(\sim 65-75 \mathrm{nM})$ were applied to primary rat astrocyte cultures pretreated with adenovirus encoding an NFAT-luciferase reporter construct (Ad-NFAT-Luc) described previously (Sama et al., 2008). Cultures were also infected with adenovirus encoding the potent NFAT inhibitor, VIVIT (Ad-VIVIT-EGFP), or adenovirus encoding $\beta$-galactosidase (Ad-LacZ, control). After $24 \mathrm{~h}$ of treatment, NFAT-dependent luciferase activity was assessed and normalized to control cultures that were preloaded with NFAT-luc and LacZ, but not exposed to $A \beta$ peptides. As shown in Figure $7 D$, all three $A \beta$ subtypes caused at least a small increase in NFAT-luc activity that was suppressed by coadministration of VIVIT. However, the largest increase in NFAT activation was clearly triggered by $\mathrm{A} \beta$ oligomers $(p<0.001$, vs all other conditions). Direct visualization of astrocytes transfected with an NFAT-EGFP fusion protein further revealed a rapid $(\sim 15$ min) redistribution of NFATs to the nucleus after treatment with oligomeric $\mathrm{A} \beta$ peptides (Fig. $7 E, F$ ). Blockade of $\mathrm{CN}$ activity during $A \beta$ application with the immunosuppressant cyclosporin A $(5 \mu \mathrm{M})$ completely prevented nuclear translocation. Thus, astrocytic CN/NFAT signaling is rapidly and robustly recruited by elevated oligomeric $\mathrm{A} \beta$ levels.

\section{Astrocytic NFAT activity, EAAT2, and $\mathrm{A} \boldsymbol{\beta}$-mediated neurotoxicity} Activation of the CN/NFAT pathway in astrocytes by inflammatory mediators, such as IL- $1 \beta$, has been shown to disrupt glutamate homeostasis and impair neuronal viability through the downregulation of astrocyte-specific excitatory amino acid transporters (EAATs), in particular EAAT2 (Sama et al., 2008). A recent report indicates that EAAT2 levels are reduced during $\mathrm{AD}$ in concert with increased astrocyte activation (Simpson et al., 2008), consistent with an increase in CN/NFAT signaling with $\mathrm{AD}$. As shown in Figure $8 \mathrm{~A}$, we also observed a progressive decline in EAAT2 protein levels in human hippocampus with $\mathrm{AD}$ ( $p \leq 0.05$, control vs $\mathrm{MCI}$; $p<0.001$, control vs $\mathrm{AD}$ ) even though levels of other membrane associated pumps, such as the $\mathrm{Na}^{+} / \mathrm{K}^{+}$ATPase, remained highly stable (data not shown). To investigate whether $A \beta$-mediated activation of the CN/NFAT pathway leads to a reduction in EAAT2 levels, we treated primary rat astrocyte cultures for $24 \mathrm{~h}$ with oligomeric $\mathrm{A} \beta$ $(\sim 65 \mathrm{nM})$ in the presence or absence of a lipid soluble VIVIT peptide and measured total EAAT2 protein using Western blot (Fig. $8 B$ ). Under these conditions, $\mathrm{A} \beta$ caused a $\sim 25 \%$ reduction $(p<0.01)$ in EAAT2 levels, which was blocked by inhibition of NFAT signaling with VIVIT. Effects of A $\beta$ on EAAT2 levels were not inhibited, and instead slightly, but significantly potentiated $(p<0.01)$, when codelivered with a control peptide (i.e., IVEET).

To determine the extent to which astrocytic CN/NFAT activity modulates extracellular glutamate levels and neuronal viability, we infected 5-week-old mixed (neuron/astrocyte) hippocampal cell cultures with adenovirus encoding VIVIT under the control of the human GFAP promoter (Ad-Gfa2-VIVIT-EGFP). The $2.2 \mathrm{~kb}$ Gfa2 promoter used here has been shown to mediate transgene expression selectively in astrocytes (Lee et al., 2008). Cultures infected with either Gfa2-VIVIT-EGFP or GFa2-EGFP (control) were then treated with $\mathrm{A} \beta$ oligomers and extracellular glutamate levels (Fig. 8C) and neuronal cell death (Fig. $8 D$ ) were quantified at 24 and $48 \mathrm{~h}$, respectively (see Materials and Methods for details). The results revealed a large and significant increase ( $p<$ 0.001 ) in both outcome measures after $A \beta$ treatment, regardless of whether VIVIT was expressed in astrocytes. Nonetheless, $A \beta$ treated cultures infected with Gfa2-VIVIT experienced $\sim 25 \%$ 
A
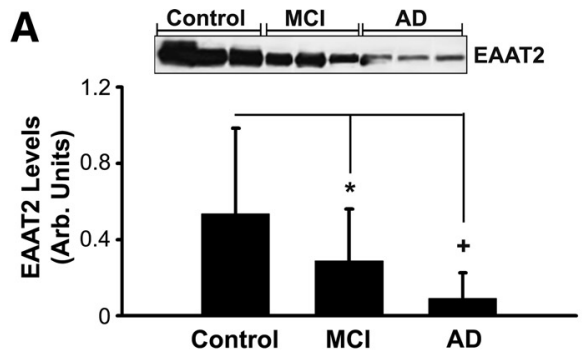

B
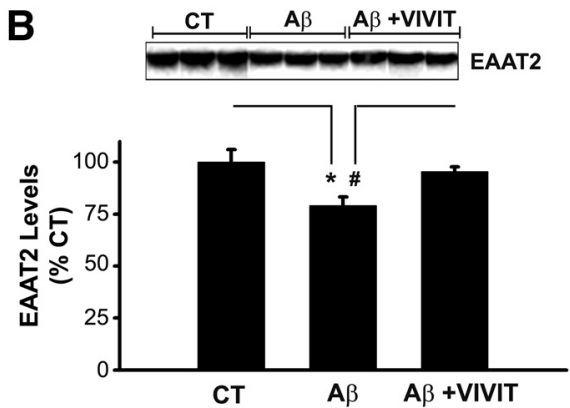

C

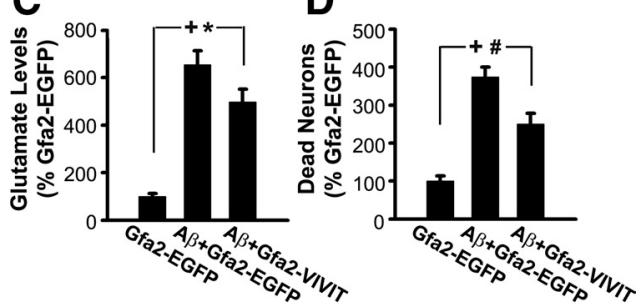

Figure 8. Downregulation of EAAT2 protein is associated with elevated glutamate levels and neurotoxicity. $\boldsymbol{A}$, Representative Western blot and graph for EAAT2 in membrane fractions prepared from hippocampal tissue samples from control, $\mathrm{MCl}$, and AD patients. EAAT2 levels drop off precipitously with $\mathrm{MCl}$ and $\mathrm{AD}$. B, Representative Western blot and graph for EAAT2 in primary rat astrocyte cultures that were untreated (control; $(\mathrm{T})$, or incubated for $24 \mathrm{~h}$ with oligomeric $A \beta(65 \mathrm{~nm})$ in the presence or absence of lipid soluble VIVIT peptide $(50 \mathrm{~nm})$. Cultures were treated $2 \mathrm{~h}$ with VIVIT before oligomeric $A \beta$ administration ( $n=4$ pooled samples per condition). Results are expressed as percentage of control (mean \pm SEM). Oligomeric $A \beta$ caused an $\sim 25 \%$ reduction in EAAT2 levels, which was blocked by VIVIT. C, D, Extracellular glutamate levels $(\boldsymbol{C})$ and number of dead neurons $(\boldsymbol{D})$ after $24-48 \mathrm{~h}$ treatment with oligomeric $\mathrm{A} \beta(65 \mathrm{nM})$. Cultures were infected $24 \mathrm{~h}$ earlier with control adenovirus (GFa2-EGFP, control) or adenovirus encoding VIVIT (Gfa2-VIVIT). The human GFAP promoter (GFa2) was used to limit transgene expression to astrocytes. Data for $C$ and $D$ are expressed as percentage of the Gfa2EGFP control condition (mean $\pm S E M$ ). Under these conditions, oligomeric $A \beta$ caused a marked increase in extracellular glutamate levels and neuronal death that was significantly alleviated by inhibiting astrocytic CN/NFAT activity with VIVIT. ${ }^{*} p \leq 0.05,{ }^{*} p<0.01,{ }^{+} p<0.001$.

lower extracellular glutamate levels and more than a third fewer dead neurons. Both of these protective effects were statistically significant $(p<0.05)$, and suggest that astrocytic CN/NFAT activity may increase neuronal vulnerability to the deleterious effects of $\mathrm{A} \beta$.

\section{Discussion}

The present study is among the first to characterize NFAT signaling properties in human $\mathrm{AD}$ brain tissue. The most significant finding was that specific NFAT isoforms exhibit a preferential shift to nuclear compartments in the hippocampus, but not the cerebellum, as a function of pathology and dementia. Some observed changes were associated with the mildest stages of cognitive decline, suggesting that the CN/NFAT pathway may be an antecedent to other pathophysological changes that arise during the course of disease. Consistent with this possibility, pathogenic $\mathrm{A} \beta$ peptides rapidly and robustly stimulated CN/NFAT activity in astrocytes, which, in turn, contributed to neuronal death in primary cell cultures. These results may provide important new insight into the molecular cascades involved in the progression of dementia and neurodegeneration with $\mathrm{AD}$.

\section{Validity of postmortem measurements}

$\mathrm{CN}$ directly and specifically mediates the translocation of NFATs from cytosol to nucleus, where NFATs remain as long as $\mathrm{CN}$ is in an activated state. The increased association of NFATs with isolated nuclear fractions from MCI and $\mathrm{AD}$ hippocampal tissue specimens suggests that CN/NFAT signaling is elevated as a function of disease state. It is unlikely that these changes were simply an artifact of PMI or the subcellular fractionation procedure for at least four reasons. First, there were no correlations between any of the biological measures reported here and PMI (which was very short, $\sim 3 \mathrm{~h}$ ). Second, multiple NFAT, CN, and GSK3- $\beta$ isoforms exhibited different levels of nuclear association in different brain regions at different stages of disease/dementia. Third, in a subset of patients, phospho-NFAT3 levels were reduced in the $\mathrm{AD}$ group, consistent with increased $\mathrm{CN}$-mediated dephosphorylation. Finally, intercorrelations among the different CN, GSK, and NFAT isoforms were entirely different between the hippocampus and cerebellum.

\section{Selective changes in NFAT isoforms with AD}

Individual NFAT isoforms share strong sequence homology and exhibit many redundant functions. Nonetheless, it is becoming increasingly clear that each isoform can also regulate unique transcriptional programs involved in initiating or maintaining changes in tissue phenotype (Crabtree and Olson, 2002; Horsley and Pavlath, 2002). Although multiple NFAT isoforms and associated splice variants have been identified in nervous tissue (Nguyen and Di Giovanni, 2008; Vihma et al., 2008), few studies have directly evaluated isoform-specific differences in distribution or function. Here, we found that NFAT1 was more strongly associated with hippocampal nuclear compartments during MCI, whereas NFAT3 showed a stronger nuclear bias in the later stages of cognitive decline. These findings suggest that NFATs may make isoform-specific contributions to the development and progression of the disease process.

Perhaps the simplest explanation for these differences is that NFATs 1 and 3 are selectively expressed in separate cell types that respond differently to disease-relevant events (e.g., oxidative stress or inflammation). However, this possibility seems unlikely because both NFATs appear in the same types (i.e., neurons and astrocytes) throughout the course of disease. Alternatively, different NFAT isoforms contained within the same cells may nonetheless uniquely respond to $\mathrm{CN}$ activation depending on the phenotypic state of the tissue, as occurs in muscle cells during myogenesis (Abbott et al., 1998). Isoform-specific nuclear accumulation of NFATs within the same cell could result from different sensitivities to $\mathrm{CN}$ isoforms. That NFAT1 correlates to the subcellular distribution of $\mathrm{CN}-\mathrm{A} \alpha$ and $\mathrm{CN}-\mathrm{A} \beta$, whereas NFAT3 preferentially correlates to $\mathrm{CN}-\mathrm{A} \alpha$ (Fig. 3 ), is consistent with this possibility. Different NFATs may also respond differently to NFAT kinases, and/or to the presence/availability of other nonNFAT transcription factors, among other things.

The unique contributions of NFATs 1 and 3 to the progression of AD are presently unclear. NFAT1 is well known to regulate cytokine expression in several peripheral cell types, suggesting that this isoform participates in neuroinflammatory responses that arise early in the progression of $\mathrm{AD}$ (Van Eldik et al., 2007). In contrast, several recent reports have shown that NFAT3 is 
involved in injury-induced neuronal death (Shioda et al., 2007; Luoma and Zirpel, 2008), which is consistent with the increased nuclear accumulation of this isoform during the advanced stages of $\mathrm{AD}$. Clearly, these potentially different roles will require further investigation.

\section{Changes in $\mathrm{CN}$ with $\mathrm{AD}$}

With the exception of Liu et al. (2005), several studies used in vitro activity assays to show a reduction (rather than an increase) in CN activity with AD (Gong et al., 1993; Ladner et al., 1996; Lian et al., 2001). In vitro assays, although highly useful for quantifying phosphatase properties and kinetics, are also necessarily conducted under artificial and highly controlled conditions, and may not accurately estimate $\mathrm{CN}$ regulation in intact tissue. Nonetheless, suppression of $\mathrm{CN}$ activity with $\mathrm{AD}$ has also been inferred from studies finding an $\mathrm{AD}$-related increase in putative CN inhibitors, such as the Down Syndrome Critical Region-1 (DSCR-1) protein (Ermak et al., 2001; Cook et al., 2005). However, DSCR-1 can apparently provide inhibitory or facilitatory control over $\mathrm{CN}$, depending on the circumstances (Hilioti et al., 2004; Sanna et al., 2006; Liu et al., 2009). Transcription of DSCR-1 is also strongly stimulated by CN/NFATs (Hilioti et al., 2004; Lange et al., 2004; Canellada et al., 2008), such that an $\mathrm{AD}$-related increase in DSCR-1 levels may be expected if $\mathrm{CN}$ activity is also elevated.

The subcellular compartmentalization of $\mathrm{CN}$ may be even more important than its overall enzymatic activity. In the nucleus, $\mathrm{CN}$ can remain bound to, and physically mask, critical nuclear export sequences on NFATs, independent of CN catalytic activity (Zhu and McKeon, 1999). A progressive increase in nuclear $\mathrm{CN}$ levels in the hippocampus with $\mathrm{AD}$, as observed here, may therefore help keep NFATs in the nucleus, leading to altered transcriptional regulation. Nuclear localization of $\mathrm{CN}$ may also impact the activity of numerous other transcription factors, such as CREB, leading to possibly complicated and diffuse changes in transcriptional activity.

\section{CN/NFAT signaling in astrocytes and $\mathrm{A} \boldsymbol{\beta}$}

The positive correlation between nuclear $\mathrm{CN}-\mathrm{A} \alpha / \mathrm{NFAT} 3$ levels and soluble $A \beta_{(1-42)}$ observed here is consistent with a growing number of studies that find increased $\mathrm{CN}$ signaling in experimental models of amyloidosis (Chen et al., 2002; Shankar et al., 2007; Agostinho et al., 2008; Kuchibhotla et al., 2008; Reese et al., 2008). Although these studies have generally held a "neuron-centric" view of $\mathrm{CN} / \mathrm{A} \beta$ interactions, the present work demonstrates that oligomeric A $\beta$ also stimulates astrocytic CN/NFAT signaling. Many amyloid deposits are enveloped by astrocytes expressing high levels of CN (Norris et al., 2005; Celsi et al., 2007) (supplemental Fig. 2, available at www.jneurosci.org as supplemental material). The intense localization of $\mathrm{CN}$ to areas of amyloid pathology may therefore expand or amplify the deleterious actions of $\mathrm{A} \beta$ to surrounding cells.

Astrocytes are responsible for removing the bulk of glutamate from the extracellular milieu, which in turn, protects neurons from excitotoxic injury. Earlier work has shown that $\mathrm{A} \beta$ peptides impair astrocytic glutamate uptake through the production of reactive oxygen species (Harris et al., 1995, 1996; Keller et al., 1997) and/or through inhibition of glucose uptake (Parpura-Gill et al., 1997). The present study found that $A \beta$ can also affect glutamate uptake in astrocytes through the downregulation of high-affinity glutamate transporters (i.e., EAAT2); an effect that was prevented by inhibition of NFAT activity. In addition, blockade of astrocytic NFAT activity ameliorated $\mathrm{A} \beta$-dependent neu- rotoxicity. Our work, together with the aforementioned studies, therefore suggests that $\mathrm{A} \beta$ disrupts glutamate homeostasis and triggers excitotoxicity through multiple cellular mechanisms. Moreover, an increase in CN/NFAT activity with AD may account, in part, for the marked reduction in EAAT2 levels during disease progression, as observed here (Fig. $8 \mathrm{~A}$ ), and previously (Simpson et al., 2008).

In contrast to the partially neuroprotective effects observed in the present report, astrocyte-specific NFAT inhibition was shown previously to provide nearly complete protection against IL- $1 \beta$ dependent toxicity (Sama et al., 2008). It deserves noting that our present and earlier studies were conducted on embryonic cultures, which have been shown to respond quite differently to $\mathrm{A} \beta$ than cultures derived from adult animals (Wyss-Coray et al., 2003; Pihlaja et al., 2008). It is therefore possible that NFAT inhibition would show greater efficacy in the presence of mature astrocytes, or in intact animals. Also, unlike IL- $1 \beta$, oligomeric A $\beta$ can directly kill neurons through several mechanisms, including an increase in membrane permeability to $\mathrm{Ca}^{2+}$ (Arispe et al., 1993; Kawahara and Kuroda, 2000; Kayed et al., 2004; Demuro et al., 2005; Sokolov et al., 2006). A $\beta$ also rapidly increases extracellular glutamate via neuronal release mechanisms (Li et al., 2009). Thus, blockade of an astrocyte-based process may not prevent the primary neuronal damage caused by $\mathrm{A} \beta$, but may prevent the secondary damage resulting from glial activation (Mrak and Griffin, 2005b; Van Eldik et al., 2007).

Suppression of glial activation may also dampen the abnormal production and/or processing of $A \beta$ (Blasko et al., 2001; Weggen et al., 2001; Morihara et al., 2002; Yan et al., 2003). Interestingly, NFATs contribute directly to $\mathrm{A} \beta$ production by stimulating BACE1 expression (Cho et al., 2008). Additional studies will be necessary to fully characterize the interactions between $A \beta$ and $\mathrm{CN} / \mathrm{NFAT}$ signaling in astrocytes and determine how these interactions lead to neurodegeneration.

\section{Summary and conclusions}

Previously, we found that increased activation of $\mathrm{CN}$ in nervous tissue recapitulates, to a highly significant degree, the transcriptional signature associated with neuroinflammation, brain aging, and early stage AD (Norris et al., 2005). The present work confirms these findings and shows for the first time that selective alterations in NFAT signaling emerge with MCI and/or are related to the progression of dementia. Further work will be necessary to characterize the isoform-specific functions of different NFATs in the disease process, as well as elucidate the interrelationships between $\mathrm{A} \beta$ and $\mathrm{CN} / \mathrm{NFAT}$ signaling in astrocytes. Nevertheless, the neuroprotective effects of NFAT inhibition observed here, and in our previous work, suggest that NFATs may be a promising molecular target for the treatment of $\mathrm{AD}$-related cognitive decline.

\section{References}

Abbott KL, Friday BB, Thaloor D, Murphy TJ, Pavlath GK (1998) Activation and cellular localization of the cyclosporine A-sensitive transcription factor NF-AT in skeletal muscle cells. Mol Biol Cell 9:2905-2916.

Agostinho P, Lopes JP, Velez Z, Oliveira CR (2008) Overactivation of calcineurin induced by amyloid-beta and prion proteins. Neurochem Int 52:1226-1233.

Akama KT, Van Eldik LJ (2000) Beta-amyloid stimulation of inducible nitricoxide synthase in astrocytes is interleukin-1beta- and tumor necrosis factoralpha (TNFalpha)-dependent, and involves a TNFalpha receptor-associated factor- and NFkappaB-inducing kinase-dependent signaling mechanism. J Biol Chem 275:7918-7924.

Akama KT, Albanese C, Pestell RG, Van Eldik LJ (1998) Amyloid betapeptide stimulates nitric oxide production in astrocytes through an 
NFkappaB-dependent mechanism. Proc Natl Acad Sci U S A 95: 5795-5800.

Aramburu J, Yaffe MB, López-Rodríguez C, Cantley LC, Hogan PG, Rao A (1999) Affinity-driven peptide selection of an NFAT inhibitor more selective than cyclosporin A. Science 285:2129-2133.

Arispe N, Rojas E, Pollard HB (1993) Alzheimer disease amyloid beta protein forms calcium channels in bilayer membranes: blockade by tromethamine and aluminum. Proc Natl Acad Sci U S A 90:567-571.

Blalock EM, Chen KC, Sharrow K, Herman JP, Porter NM, Foster TC, Landfield PW (2003) Gene microarrays in hippocampal aging: statistical profiling identifies novel processes correlated with cognitive impairment. J Neurosci 23:3807-3819.

Blalock EM, Geddes JW, Chen KC, Porter NM, Markesbery WR, Landfield PW (2004) Incipient Alzheimer's disease: microarray correlation analyses reveal major transcriptional and tumor suppressor responses. Proc Natl Acad Sci U S A 101:2173-2178.

Blasko I, Apochal A, Boeck G, Hartmann T, Grubeck-Loebenstein B, Ransmayr G (2001) Ibuprofen decreases cytokine-induced amyloid beta production in neuronal cells. Neurobiol Dis 8:1094-1101.

Canellada A, Ramirez BG, Minami T, Redondo JM, Cano E (2008) Calcium/ calcineurin signaling in primary cortical astrocyte cultures: Rcan1-4 and cyclooxygenase-2 as NFAT target genes. Glia 56:709-722.

Celsi F, Svedberg M, Unger C, Cotman CW, Carrì MT, Ottersen OP, Nordberg A, Torp R (2007) Beta-amyloid causes downregulation of calcineurin in neurons through induction of oxidative stress. Neurobiol Dis 26:342-352.

Chen QS, Wei WZ, Shimahara T, Xie CW (2002) Alzheimer amyloid betapeptide inhibits the late phase of long-term potentiation through calcineurin-dependent mechanisms in the hippocampal dentate gyrus. Neurobiol Learn Mem 77:354-371.

Cho HJ, Jin SM, Youn HD, Huh K, Mook-Jung I (2008) Disrupted intracellular calcium regulates BACE1 gene expression via nuclear factor of activated T cells 1 (NFAT 1) signaling. Aging Cell 7:137-147.

Cook CN, Hejna MJ, Magnuson DJ, Lee JM (2005) Expression of calcipres$\sin 1$, an inhibitor of the phosphatase calcineurin, is altered with aging and Alzheimer's disease. J Alzheimers Dis 8:63-73.

Crabtree GR, Olson EN (2002) NFAT signaling: choreographing the social lives of cells. Cell 109 Suppl:S67-79.

Demuro A, Mina E, Kayed R, Milton SC, Parker I, Glabe CG (2005) Calcium dysregulation and membrane disruption as a ubiquitous neurotoxic mechanism of soluble amyloid oligomers. J Biol Chem 280:17294-17300.

Dineley KT, Hogan D, Zhang WR, Taglialatela G (2007) Acute inhibition of calcineurin restores associative learning and memory in Tg2576 APP transgenic mice. Neurobiol Learn Mem 88:217-224.

Ermak G, Morgan TE, Davies KJ (2001) Chronic overexpression of the calcineurin inhibitory gene DSCR1 (Adapt78) is associated with Alzheimer's disease. J Biol Chem 276:38787-38794.

Fernandez AM, Fernandez S, Carrero P, Garcia-Garcia M, Torres-Aleman I (2007) Calcineurin in reactive astrocytes plays a key role in the interplay between proinflammatory and anti-inflammatory signals. J Neurosci $27: 8745-8756$.

Ferraccioli GF, Tomietto P, De Santis M (2005) Rationale for T cell inhibition by cyclosporin A in major autoimmune diseases. Ann N Y Acad Sci 1051:658-665.

Foster TC, Sharrow KM, Masse JR, Norris CM, Kumar A (2001) Calcineurin links $\mathrm{Ca}^{2+}$ dysregulation with brain aging. J Neurosci 21:4066-4073.

Genoux D, Haditsch U, Knobloch M, Michalon A, Storm D, Mansuy IM (2002) Protein phosphatase 1 is a molecular constraint on learning and memory. Nature 418:970-975.

Gong CX, Singh TJ, Grundke-Iqbal I, Iqbal K (1993) Phosphoprotein phosphatase activities in Alzheimer disease brain. J Neurochem 61:921-927.

Graef IA, Mermelstein PG, Stankunas K, Neilson JR, Deisseroth K, Tsien RW, Crabtree GR (1999) L-type calcium channels and GSK-3 regulate the activity of NF-ATc4 in hippocampal neurons. Nature 401:703-708.

Groth RD, Dunbar RL, Mermelstein PG (2003) Calcineurin regulation of neuronal plasticity. Biochem Biophys Res Commun 311:1159-1171.

Harris ME, Carney JM, Cole PS, Hensley K, Howard BJ, Martin L, Bummer P, Wang Y, Pedigo NW Jr, Butterfield DA (1995) beta-Amyloid peptidederived, oxygen-dependent free radicals inhibit glutamate uptake in cultured astrocytes: implications for Alzheimer's disease. Neuroreport 6:1875-1879.
Harris ME, Wang Y, Pedigo NW Jr, Hensley K, Butterfield DA, Carney JM (1996) Amyloid beta peptide (25-35) inhibits $\mathrm{Na}+$-dependent glutamate uptake in rat hippocampal astrocyte cultures. J Neurochem 67:277-286.

Hashimoto T, Kawamata T, Saito N, Sasaki M, Nakai M, Niu S, Taniguchi T, Terashima A, Yasuda M, Maeda K, Tanaka C (1998) Isoform-specific redistribution of calcineurin A alpha and A beta in the hippocampal CAI region of gerbils after transient ischemia. J Neurochem 70:1289-1298.

Heineke J, Molkentin JD (2006) Regulation of cardiac hypertrophy by intracellular signalling pathways. Nat Rev Mol Cell Biol 7:589-600.

Hilioti Z, Gallagher DA, Low-Nam ST, Ramaswamy P, Gajer P, Kingsbury TJ, Birchwood CJ, Levchenko A, Cunningham KW (2004) GSK-3 kinases enhance calcineurin signaling by phosphorylation of RCNs. Genes Dev 18:35-47.

Hogan PG, Chen L, Nardone J, Rao A (2003) Transcriptional regulation by calcium, calcineurin, and NFAT. Genes Dev 17:2205-2232.

Horsley V, Pavlath GK (2002) NFAT: ubiquitous regulator of cell differentiation and adaptation. J Cell Biol 156:771-774.

Kaminuma O (2008) Selective inhibitors of nuclear factor of activated T cells: potential therapeutic drugs for the treatment of immunological and inflammatory diseases. Inflamm Allergy Drug Targets 7:35-40.

Kawahara M, Kuroda Y (2000) Molecular mechanism of neurodegeneration induced by Alzheimer's beta-amyloid protein: channel formation and disruption of calcium homeostasis. Brain Res Bull 53:389-397.

Kayed R, Sokolov Y, Edmonds B, McIntire TM, Milton SC, Hall JE, Glabe CG (2004) Permeabilization of lipid bilayers is a common conformationdependent activity of soluble amyloid oligomers in protein misfolding diseases. J Biol Chem 279:46363-46366.

Keller JN, Pang Z, Geddes JW, Begley JG, Germeyer A, Waeg G, Mattson MP (1997) Impairment of glucose and glutamate transport and induction of mitochondrial oxidative stress and dysfunction in synaptosomes by amyloid beta-peptide: role of the lipid peroxidation product 4-hydroxynonenal. J Neurochem 69:273-284.

Kuchibhotla KV, Goldman ST, Lattarulo CR, Wu HY, Hyman BT, Bacskai BJ (2008) Abeta plaques lead to aberrant regulation of calcium homeostasis in vivo resulting in structural and functional disruption of neuronal networks. Neuron 59:214-225.

Ladner CJ, Czech J, Maurice J, Lorens SA, Lee JM (1996) Reduction of calcineurin enzymatic activity in Alzheimer's disease: correlation with neuropathologic changes. J Neuropathol Exp Neurol 55:924-931.

Lange AW, Molkentin JD, Yutzey KE (2004) DSCR1 gene expression is dependent on NFATc1 during cardiac valve formation and colocalizes with anomalous organ development in trisomy 16 mice. Dev Biol 266:346-360

Lee Y, Messing A, Su M, Brenner M (2008) GFAP promoter elements required for region-specific and astrocyte-specific expression. Glia 56:481-493.

LeVine H 3rd (1999) Quantification of beta-sheet amyloid fibril structures with thioflavin T. Methods Enzymol 309:274-284.

LeVine H 3rd (2004) Alzheimer's beta-peptide oligomer formation at physiologic concentrations. Anal Biochem 335:81-90.

Li S, Hong S, Shepardson NE, Walsh DM, Shankar GM, Selkoe D (2009) Soluble oligomers of amyloid beta protein facilitate hippocampal longterm depression by disrupting neuronal glutamate uptake. Neuron 62 : $788-801$.

Lian Q, Ladner CJ, Magnuson D, Lee JM (2001) Selective changes of calcineurin (protein phosphatase 2B) activity in Alzheimer's disease cerebral cortex. Exp Neurol 167:158-165.

Liu F, Grundke-Iqbal I, Iqbal K, Oda Y, Tomizawa K, Gong CX (2005) Truncation and activation of calcineurin A by calpain I in Alzheimer disease brain. J Biol Chem 280:37755-37762.

Liu Q, Busby JC, Molkentin JD (2009) Interaction between TAK1-TAB1TAB2 and RCAN1-calcineurin defines a signalling nodal control point. Nat Cell Biol 11:154-161.

Lund P (1986) L-Glutamine and L-glutamate: UV-method with glutaminase and glutamate dehydrogenase. In: Methods of enzymatic analysis, Vol 8 (Bergmeyer HU, ed). Weinheim, Germany: VCH Verlagsgesellschaft.

Luoma JI, Zirpel L (2008) Deafferentation-induced activation of NFAT (nuclear factor of activated T-cells) in cochlear nucleus neurons during a developmental critical period: a role for NFATc4-dependent apoptosis in the CNS. J Neurosci 28:3159-3169. 
McGowan E, Pickford F, Kim J, Onstead L, Eriksen J, Yu C, Skipper L, Murphy MP, Beard J, Das P, Jansen K, Delucia M, Lin WL, Dolios G, Wang R, Eckman CB, Dickson DW, Hutton M, Hardy J, Golde T (2005) Abeta42 is essential for parenchymal and vascular amyloid deposition in mice. Neuron 47:191-199.

McKhann G, Drachman D, Folstein M, Katzman R, Price D, Stadlan EM (1984) Clinical diagnosis of Alzheimer's disease: report of the NINCDSADRDA Work Group under the auspices of Department of Health and Human Services Task Force on Alzheimer's Disease. Neurology 34:939-944.

Mirra SS, Heyman A, McKeel D, Sumi SM, Crain BJ, Brownlee LM, Vogel FS, Hughes JP, van Belle G, Berg L (1991) The Consortium to Establish a Registry for Alzheimer's Disease (CERAD). Part II. Standardization of the neuropathologic assessment of Alzheimer's disease. Neurology 41:479-486.

Morihara T, Chu T, Ubeda O, Beech W, Cole GM (2002) Selective inhibition of Abeta42 production by NSAID R-enantiomers. J Neurochem 83:1009-1012.

Mrak RE, Griffin WS (2005a) Glia and their cytokines in progression of neurodegeneration. Neurobiol Aging 26:349-354.

Mrak RE, Griffin WS (2005b) Potential inflammatory biomarkers in Alzheimer's disease. J Alzheimers Dis 8:369-375.

Murphy MP, Beckett TL, Ding Q, Patel E, Markesbery WR, St Clair DK, LeVine H 3rd, Keller JN (2007) Abeta solubility and deposition during $\mathrm{AD}$ progression and in APPxPS-1 knock-in mice. Neurobiol Dis 27:301-311.

National Institute on Aging, and Reagan Institute Working Group on Diagnostic Criteria for the Neuropathological Assessment of Alzheimer's Disease (1997) Consensus recommendations for the postmortem diagnosis of Alzheimer's disease. Neurobiol Aging 18:S1-S2.

Nelson PT, Jicha GA, Schmitt FA, Liu H, Davis DG, Mendiondo MS, Abner EL, Markesbery WR (2007) Clinicopathologic correlations in a large Alzheimer disease center autopsy cohort: neuritic plaques and neurofibrillary tangles "do count" when staging disease severity. J Neuropathol Exp Neurol 66:1136-1146.

Nguyen T, Di Giovanni S (2008) NFAT signaling in neural development and axon growth. Int J Dev Neurosci 26:141-145.

Noguchi H, Matsushita M, Okitsu T, Moriwaki A, Tomizawa K, Kang S, Li ST, Kobayashi N, Matsumoto S, Tanaka K, Tanaka N, Matsui H (2004) A new cell-permeable peptide allows successful allogeneic islet transplantation in mice. Nat Med 10:305-309.

Norris CM, Blalock EM, Chen KC, Porter NM, Landfield PW (2002) Calcineurin enhances L-type $\mathrm{Ca}(2+)$ channel activity in hippocampal neurons: increased effect with age in culture. Neuroscience 110:213-225.

Norris CM, Kadish I, Blalock EM, Chen KC, Thibault V, Porter NM, Landfield PW, Kraner SD (2005) Calcineurin triggers reactive/inflammatory processes in astrocytes and is upregulated in aging and Alzheimer's models. J Neurosci 25:4649-4658.

Norris CM, Blalock EM, Thibault O, Brewer LD, Clodfelter GV, Porter NM, Landfield PW (2006) Electrophysiological mechanisms of delayed excitotoxicity: positive feedback loop between NMDA receptor current and depolarization-mediated glutamate release. J Neurophysiol 96:24882500.

Norris CM, Blalock EM, Chen KC, Porter NM, Thibault O, Kraner SD, Landfield PW (2008) Hippocampal 'zipper' slice studies reveal a necessary role for calcineurin in the increased activity of L-type $\mathrm{Ca}(2+)$ channels with aging. Neurobiol Aging. Advance online publication. Retrieved May 7, 2008. doi:10.1016/j.neurobiolaging.2008.03.026

Ohlsson H, Edlund T (1986) Sequence-specific interactions of nuclear factors with the insulin gene enhancer. Cell 45:35-44.

Parpura-Gill A, Beitz D, Uemura E (1997) The inhibitory effects of betaamyloid on glutamate and glucose uptakes by cultured astrocytes. Brain Res 754:65-71.
Petersen RC, Smith GE, Waring SC, Ivnik RJ, Tangalos EG, Kokmen E (1999) Mild cognitive impairment: clinical characterization and outcome. Arch Neurol 56:303-308.

Pihlaja R, Koistinaho J, Malm T, Sikkilä H, Vainio S, Koistinaho M (2008) Transplanted astrocytes internalize deposited beta-amyloid peptides in a transgenic mouse model of Alzheimer's disease. Glia 56:154-163.

Porter NM, Thibault O, Thibault V, Chen KC, Landfield PW (1997) Calcium channel density and hippocampal cell death with age in long-term culture. J Neurosci 17:5629-5639.

Reese LC, Zhang W, Dineley KT, Kayed R, Taglialatela G (2008) Selective induction of calcineurin activity and signaling by oligomeric amyloid beta. Aging Cell 7:824-835.

Sama MA, Mathis DM, Furman JL, Abdul HM, Artiushin IA, Kraner SD, Norris CM (2008) Interleukin-1beta-dependent signaling between astrocytes and neurons depends critically on astrocytic calcineurin/NFAT activity. J Biol Chem 283:21953-21964.

Sanna B, Brandt EB, Kaiser RA, Pfluger P, Witt SA, Kimball TR, van Rooij E, De Windt LJ, Rothenberg ME, Tschop MH, Benoit SC, Molkentin JD (2006) Modulatory calcineurin-interacting proteins 1 and 2 function as calcineurin facilitators in vivo. Proc Natl Acad Sci U S A 103:7327-7332.

Shankar GM, Bloodgood BL, Townsend M, Walsh DM, Selkoe DJ, Sabatini BL (2007) Natural oligomers of the Alzheimer amyloid-beta protein induce reversible synapse loss by modulating an NMDA-type glutamate receptor-dependent signaling pathway. J Neurosci 27:2866-2875.

Shioda N, Han F, Moriguchi S, Fukunaga K (2007) Constitutively active calcineurin mediates delayed neuronal death through Fas-ligand expression via activation of NFAT and FKHR transcriptional activities in mouse brain ischemia. J Neurochem 102:1506-1517.

Sierra-Paredes G, Sierra-Marcuño G (2008) Ascomycin and FK506: pharmacology and therapeutic potential as anticonvulsants and neuroprotectants. CNS Neurosci Ther 14:36-46.

Simpson JE, Ince PG, Lace G, Forster G, Shaw PJ, Matthews F, Savva G, Brayne C, Wharton SB (2008) Astrocyte phenotype in relation to Alzheimer-type pathology in the ageing brain. Neurobiol Aging. Advance online publication. Retrieved June 30, 2009. doi:10.1016/j.neurobiolaging.2008.05.015.

Sokolov Y, Kozak JA, Kayed R, Chanturiya A, Glabe C, Hall JE (2006) Soluble amyloid oligomers increase bilayer conductance by altering dielectric structure. J Gen Physiol 128:637-647.

Van Eldik LJ, Thompson WL, Ralay Ranaivo H, Behanna HA, Martin Watterson D (2007) Glia proinflammatory cytokine upregulation as a therapeutic target for neurodegenerative diseases: function-based and target-based discovery approaches. Int Rev Neurobiol 82:277-296.

Vihma H, Pruunsild P, Timmusk T (2008) Alternative splicing and expression of human and mouse NFAT genes. Genomics 92:279-291.

Weggen S, Eriksen JL, Das P, Sagi SA, Wang R, Pietrzik CU, Findlay KA, Smith TE, Murphy MP, Bulter T, Kang DE, Marquez-Sterling N, Golde TE, Koo EH (2001) A subset of NSAIDs lower amyloidogenic Abeta42 independently of cyclooxygenase activity. Nature 414:212-216.

Wilkins BJ, Dai YS, Bueno OF, Parsons SA, Xu J, Plank DM, Jones F, Kimball TR, Molkentin JD (2004) Calcineurin/NFAT coupling participates in pathological, but not physiological, cardiac hypertrophy. Circ Res 94:110-118.

Wyss-Coray T (2006) Inflammation in Alzheimer disease: driving force, bystander or beneficial response? Nat Med 12:1005-1015.

Wyss-Coray T, Loike JD, Brionne TC, Lu E, Anankov R, Yan F, Silverstein SC, Husemann J (2003) Adult mouse astrocytes degrade amyloid-beta in vitro and in situ. Nat Med 9:453-457.

Yan Q, Zhang J, Liu H, Babu-Khan S, Vassar R, Biere AL, Citron M, Landreth G (2003) Anti-inflammatory drug therapy alters beta-amyloid processing and deposition in an animal model of Alzheimer's disease. J Neurosci 23:7504-7509.

Zhu J, McKeon F (1999) NF-AT activation requires suppression of Crm1dependent export by calcineurin. Nature 398:256-260. 